\title{
Journal of Behavioral Medicine Theory-based predictors of multiple clinician behaviors in the management of diabetes
}

Justin Presseau, Marie Johnston, Jill J Francis, Susan Hrisos, Elaine Stamp, Nick Steen, Gillian Hawthorne, Jeremy M Grimshaw, Marko Elovainio, Margaret Hunter and Martin P Eccles

\section{CITATION}

Presseau, J., Johnston, M., Francis, J.J., Hrisos, S., Stamp, E., Steen, N., Hawthorne, G., Grimshaw, J.M., Elovainio, M., Hunter, M., Eccles, M.P. (2014). Theory-based predictors of multiple clinician behaviors in the management of diabetes. Journal of Behavioral Medicine, 37, 607-620. DOI: 10.1007/s10865-013-9513-x 
Running head: PREDICTORS OF CLINICIAN BEHAVIORS IN MANAGING DIABETES

Theory-based Predictors of Multiple Clinician Behaviors in the Management of Diabetes

\author{
Justin Presseau \\ Newcastle University, UK \\ Marie Johnston \\ University of Aberdeen, UK \\ Jill J Francis \\ City University London \\ Susan Hrisos, Elaine Stamp, and Nick Steen \\ Newcastle University, UK \\ Gillian Hawthorne
}

The Newcastle upon Tyne Hospitals NHS Foundation Trust, UK

Jeremy M Grimshaw

Department of Medicine, University of Ottawa and Clinical Epidemiology Program, Ottawa

Hospital Research Institute, Canada

Marko Elovainio

National Institute for Health and Welfare, Finland

Margaret Hunter and Martin P Eccles

Newcastle University, UK 


\section{Author Note}

Justin Presseau, justin.presseau@ncl.ac.uk, Institute of Health and Society, Newcastle University, UK; Marie Johnston, m.johnston@abdn.ac.uk, College of Life Sciences and Medicine, University of Aberdeen, UK; Jill J Francis, Jill.Francis1@ @ity.ac.uk, School of Health Sciences, City University London, UK; Susan Hrisos, susan.hrisos@ncl.ac.uk, Institute of Health and Society, Newcastle University, UK; Elaine Stamp, elaine.stamp@ncl.ac.uk, Institute of Health and Society, Newcastle University, UK; Nick Steen, nick.steen@ncl.ac.uk, Institute of Health and Society, Newcastle University, UK; Gillian Hawthorne, Gillian.Hawthorne@newcastle-pct.nhs.uk, The Newcastle upon Tyne Hospitals NHS Foundation Trust, UK; Jeremy M Grimshaw, jgrimshaw @ohri.ca, Department of Medicine, University of Ottawa, and Clinical Epidemiology Program, Ottawa Hospital Research Institute, Ontario, Canada; Marko Elovainio, marko.elovainio@ thl.fi, National Institute for Health and Welfare, Finland; Margaret Hunter, gwhunter@btinternet.com, Institute of Health and Society, Newcastle University, UK; Martin P Eccles, martin.eccles@ncl.ac.uk, Institute of Health and Society, Newcastle University, UK.

The research was supported by a grant from Diabetes UK (http://www.diabetes.org.uk/). JMG holds a Canada Research Chair in Health Knowledge Transfer and Uptake. JJF is funded by the Chief Scientist Office of the Scottish Government Health Directorates. The authors would like to thank the clinicians involved for their participation.

Correspondence concerning this article should be addressed to Justin Presseau, Institute of Health and Society, Newcastle University, Baddiley-Clark Building, Richardson Road, Newcastle Upon Tyne, NE2 4AX, United Kingdom. Email: justin.presseau@ncl.ac.uk 


\begin{abstract}
Behavioral theory is often tested on one behavior in isolation from other behaviors and theories. We aimed to test the predictive validity of constructs from motivation and action theories of behavior across six diabetes-related clinician behaviors, within the same sample of primary care clinicians. Physicians and nurses $(n=427$ from 99 practices in the United Kingdom) completed questionnaires at baseline and 12 months. Primary outcomes: six selfreported clinician behaviors related to advising, prescribing and examining measured at 12 months; secondary outcomes: baseline intention and patient-scenario-based simulated behavior. Across six behaviors, each theory accounted for a medium amount of variance for 12-month behavior (median $R_{\text {adj }}^{2}=0.15$ ), large and medium amount of variance for two intention measures (median $R_{\text {adj }}^{2}=0.66 ; 0.34$ ), and small amount of variance for simulated behavior (median $R_{\text {adj }}^{2}=0.05$ ). Intention/proximal goals, self-efficacy, and habit predicted all behaviors. Constructs from social cognitive theory (self-efficacy), learning theory (habit) and action and coping planning consistently predicted multiple clinician behaviors and should be targeted by quality improvement interventions.
\end{abstract}

Keywords: clinician behavior; intention; habit; multiple behaviors; planning; self-efficacy. 
There is enduring clinical and policy interest in promoting evidence-based health care. However, the production and dissemination of evidence of clinical best practice does not automatically lead to implementation. The importance of the use of theory to understand clinician behavior and to inform the choice of change interventions to improve care is well acknowledged (Godin, Bélanger-Gravel, Eccles, \& Grimshaw, 2008; Grol, Bosch, Hulscher, Eccles, \& Wensing, 2007; Michie, Johnston, Francis, Hardeman, \& Eccles, 2008). One important step in this process is to identify how well theoretical models predict clinician behaviors. A number of studies have tested the constructs in social cognition models as predictors of clinician behavior. Most of these have been applied to predict a single behavior using a single theory, and on average explain $31 \%\left(R^{2}\right.$ range $<0.01$ to 0.58$)$ of its variability (Godin et al., 2008). This range has been assumed to be due to variation in behaviors or respondents, or to methodological issues. The present study aimed to test these assumptions directly by investigating relationships between constructs from predominant theories of behavior in the same clinicians, as predictors of multiple clinician behaviors in the context of diabetes care in the primary care setting.

With a prevalence of over 5\% (NHS_Information_Centre, 2010) complications related to Type 2 diabetes are an important cause of avoidable mortality (Adler et al., 2000). In the United Kingdom, people with diabetes are primarily managed by the integrated activities of primary care teams composed of general practitioners and practice nurses. Clinically important clinician behaviors in diabetes management are often not optimally performed (NHS_Information_Centre, 2010), reflecting underlying challenges in diabetes care. For instance, UK recommendations include a set of nine processes of care that adults with Type 2 diabetes should receive on an annual basis, including: screening for risk factors such as body mass index, blood pressure, smoking status, blood glucose and cholesterol and tests for complications relating to feet, eyes, microalbumin:creatinine ratio and creatinine 
levels (National Institute for Health and Clinical Excellence, 2008). National diabetes audit data from England show that only $54.3 \%$ of people with diabetes had been provided with all nine processes of care between January 2010 and March 2011 and considerable variability across the country (HSCIC, 2012). There is a need to better understand the theory-based factors that explain the variability in care provided by clinicians to inform quality improvement efforts. Motivation and action theories of behavior provide a basis for understanding variability in clinician behavior, though are largely tested at the clinician level only. The present study also aimed to test each theory at the clinician and organization (i.e., practice) level.

\section{Theories of Behavior Tested in this Study}

The rationale for selecting the theories investigated in this study was to reflect those tested in the 'PRocess modeling in ImpleMEntation' (PRIME) study, where multiple models were used to predict five clinical behaviors in five different samples of clinicians (Bonetti et al., 2010; Bonetti et al., 2006; Eccles et al., 2007; Grimshaw et al., 2011). The present research, the 'improving Quality in Diabetes (iQuaD)' study, builds on PRIME by aiming to test theories across multiple behaviors within the same clinicians.

The Theory of Planned Behavior (TPB) is the most commonly tested theory of health professional behavior (Godin et al., 2008) and suggests that behavior is a function of beliefs that influence intention which, along with perceived behavioral control, determine behavior (Ajzen, 1991). Attitude towards the behavior and subjective norm are both central to the model, operating on behavior via their influence on intention. The TPB provides a parsimonious account of the predictors of intention and behavior, with evidence supporting its hypotheses (Godin et al., 2008).

A number of other potentially relevant theories apply to predicting health professional behavior, though they have not been tested as frequently as the TPB. Social Cognitive Theory 
(SCT) is a broad theory of motivation and action which views behavior as reciprocally influenced by individual and environmental factors (Bandura, 1986). SCT accords a central role to self-efficacy in determining motivation and action. When operationalized as a social cognition model, SCT proposes three direct predictors of clinical behavior: Proximal goals that are equivalent to intention (cf. (Bandura, 1998), self-efficacy, and outcome expectations. The latter involve physical, social and self-evaluative expectations of performing the behavior, akin to attitude and subjective norm in the TPB (cf. (Bandura, 1998)].

Clinician behaviors are likely the result of more than health professionals being motivated and feeling capable of engaging in evidence-based behaviors. Some clinician behaviors may be performed in a habitual manner in light of anticipated consequences such that their enactment in everyday practice does not necessarily depend solely on a reasoned process of deliberation. The premise of Learning Theory is that behavior is shaped by antecedents and consequences and that repeated exposure leads to habit formation (Blackman, 1974). Within Learning Theory, clinician behavior can be viewed as a function of two constructs: the anticipated consequences of engaging in a behavior and the antecedents that trigger its pursuit (i.e., habitual responses to environmental cues); both operating largely without reasoned deliberation (Blackman, 1974; Bonetti et al., 2010; Bonetti et al., 2006; Eccles et al., 2007; Grimshaw et al., 2011; Walker et al., 2003). Applied to clinician behavior often characterized by stable contexts replete with cues to action, habit is a potentially important yet surprisingly understudied and under-theorized feature of clinician behavior that was found to be an important predictor in the PRIME studies (Bonetti et al., 2010; Bonetti et al., 2006; Eccles et al., 2007; Grimshaw et al., 2011; Walker et al., 2003). Habit was operationalized in PRIME as involving contextually triggered automaticity and routinized behavior. Alternative conceptualizations view and measure habit as involving not only automaticity, but also self-identity and a history of repetition (Verplanken \& Orbell, 2003). 
Contemporary theorizing recognizes that clinician intention is often strong but gaps in care persist, due both to the parallel operation of habitual processes and to post-intentional deliberative processes. Post-intentional processes have been proposed to explain gaps between motivation and action. Planning when, where and how an intended behavior will be enacted (action planning) is a form of prospective planning based on the premise that prespecifying the conditions under which a behavior is to be performed increases the likelihood that it will be enacted when the specified conditions present themselves (Sniehotta, Schwarzer, Scholz, \& Shuz, 2005). However, factors may impede the enactment of a behavior despite strong action plans. Forming plans to circumvent anticipated barriers to action (i.e., coping plans) shifts the burden of decision making away from the context itself, allowing for rapid enactment of behavioral alternatives in the face of these barriers in context (Sniehotta et al., 2005).

A number of studies have broadened the scope of theories applied to predict health professional behavior. Across the PRIME studies, constructs from the TPB, SCT, Learning Theory, and Planning accounted for significant variability in health professional intention (22-58\%) and behavior (simulated behavior assessed using responses to patient scenarios: 231\%; objectively recorded: 2-13\%) (Bonetti et al., 2010; Bonetti et al., 2006; Eccles et al., 2007; Grimshaw et al., 2011).

While a feature of clinician behaviors are that they have consequences of enactment beyond the actor i.e., for the patient, these theories operate similarly in clinician behaviors as in other health behaviors (e.g., healthy eating, physical activity). Meta-analytic evidence demonstrates the large evidence base showing that theoretical models provide a consistent prediction of clinician behavior across contexts, with the variability and size of effects consistent with applications of theory to health behaviors (Godin et al., 2008). However, it is not clear how these theories prospectively predict different behaviors measured in the same 
sample of clinicians and in contexts of team-based diabetes care. The study was considered exploratory, with a view to identifying which constructs from which theoretical models predict which clinical behaviors; no explicit hypotheses beyond those made by the respective theories were formed.

\section{Methods}

\section{The Improving Quality of Care in Diabetes Study}

We conducted a large prospective study to identify individual and organizational factors that predict the implementation of best care for people with diabetes managed in primary care (Eccles, Hawthorne, et al., 2009). This study was designed to predict intention and simulated behavior cross-sectionally, and behavior prospectively over 12 months, from theories of behavior. We have reported elsewhere the details of instrument development, data collection and characteristics of staff and measures (Eccles et al., 2011). Supplemental File 1 presents the flow chart from the wider study. In summary, primary care doctors and nurses from 99 general practices were recruited from a representative network of practices from across the United Kingdom. Participating practices were compensated for staff time taken to complete study materials. We identified six clinician behaviors deliberately chosen to reflect clinically important yet challenging features of diabetes care, covering a range of clinical activities recommended as best practice as described by national guidelines. The specific behaviors investigated were: 1) giving advice about weight management to patients with a BMI above a target of $30 \mathrm{~kg} / \mathrm{m}^{2}$ even following previous management (Behavior weight $_{\text {) }}$, 2) prescribing additional antihypertensive drugs to patients whose $\mathrm{BP}$ is $5 \mathrm{mmHg}$ above a target of $140 \mathrm{mmHg}$ systolic or $80 \mathrm{mmHg}$ diastolic $\mathrm{BP}$ (Behavior ${ }_{\mathrm{BP}}$ ), 3) examining foot sensation and circulation (Behavior feet $), 4)$ providing advice about self-management (Behavior self-man $_{\text {, }}$, 5) prescribing additional therapy for glycemic control in patients whose $\mathrm{HbAlc}$ is higher than 
$8 \%$ despite maximum dosage on two oral hypoglycaemic drugs (Behavior ${ }_{\mathrm{HbAlc}}$ ), and 6) providing general education about diabetes (Behavior edu $_{\text {). }}$.

At baseline, theoretical constructs and simulated behavior were assessed, then each behavior was self-reported 12 months later. We developed study questionnaires in accordance with the study protocol (Eccles, Hawthorne, et al., 2009), with one exception: we excluded anticipated regret as it is not included in the core theories under investigation. Each behavior and all items were specified in terms of the Target, Action, Context and Time (Fishbein, 1967). Study materials were piloted with clinicians from two practices in England, who were excluded from the main study.

\section{Baseline measures}

All baseline measures were behaviorally specific to each of the six clinician behaviors.

Theory of Planned Behavior (TPB). Items measuring TPB constructs were developed based on established methods (Francis et al., 2004). Items shared a common wording across the six behaviors, varying only in the action specified. Attitude items focused on 'instrumental' attitudes. Subjective norm items focused on 'injunctive' norms. Perceived behavioral control items focused on confidence in performing each behavior. We assessed clinicians' intention to engage in each behavior in two ways: level of agreement with statements of intention to engage in each behavior (intention strength) and the number of patients with whom they intended to engage in each behavior (direct estimation of intention).

Social Cognitive Theory (SCT). Self-efficacy items assessed clinicians' confidence in their capability to engage in each behavior despite potential obstacles of varying levels of challenge, as recommended (Bandura, 2006). Scales included obstacles present across the behaviors - e.g., the clinic is busy and I am running 20 minutes late) - and obstacles specific to each behavior, e.g., patient has side effects on current antihypertensive medication (for 
prescribing additional antihypertensives)]. Outcome expectations have been conceptualized as equivalent to the attitudinal and normative constructs in the TPB (Bandura, 1998; Bonetti et al., 2010; Bonetti et al., 2006; Eccles et al., 2007; Grimshaw et al., 2011). We used attitude items supplemented by a particular subjective norm item focusing on perceived social outcomes as a measure of outcome expectations in SCT. Bandura has also previously suggested that "intentions are essentially proximal goals" [(Bandura, 1998) p. 628] within SCT. We used the same items used to measure intention strength in the TPB as a measure of proximal goals in SCT.

Learning Theory (LT). Anticipated consequences were assessed using two items focusing on negative consequences, for the clinician, of performing the behavior. Evidence of habit was used to indicate the extent that clinicians had a habitual response to environmental cues, i.e., to which discriminant stimuli were present. This is a previously developed and tested (in PRIME) two-item habit measure shown to be predictive of clinician behavior.

Habit. Habit was also assessed using the 12-item self-reported habit index (Verplanken \& Orbell, 2003), with a modified stem reflecting the target, action, context and time for each behavior.

Planning. Action planning and coping planning was assessed using previously validated scales (Sniehotta et al., 2005) adapted to the clinician behaviors. Coping planning scales were informed by the list of potential obstacles to engaging in each behavior, developed for the self-efficacy scales, to assess whether clinicians reported forming coping plans to deal with situations presenting with these obstacles.

Simulated Behavior. We developed four patient scenarios to simulate clinical consultations in which the target behaviors might be performed. The scenarios were presented as a summary sheet for each of four fictional patients' clinical records detailing a patient's active health issues, past medical history, allergies, smoking and employment status, 
current medication, name and age. Details were provided of their five-year history of diabetes care, including past measures of HbA1c, cholesterol, systolic and diastolic blood pressure, albumin:creatinine ratio, body mass index, and an indication of whether/when: their feet had been inspected, and they had been provided with general patient education, weight management and self-management advice. Clinicians were asked to report whether they would do or would do if they had time address each area of diabetes care if the patient presented themselves for a 15 minute consultation. Each would do response was scored as a 2 while each would do if time was scored as 1, forming a score out of eight for each behavior.

Scales. We used 7-point Likert scales ranging from 1-strongly disagree to 7-strongly agree to measure all theoretical constructs, except direct estimation of intention. The latter was measured using the same scale as the 12 month follow-up self-report of behavior measure, representing the number of patients from 0 to 10 for whom the clinician intended to perform each behavior. High scores indicated cognitions in favor of the behavior. Scale development was informed by the PRIME project (Walker et al., 2003). Example items for each construct are presented in Supplemental File 2.

\section{Follow-up measures}

Primary Dependent Variable: Self-reported behavior (12 months). We assessed performance of all six behaviors at 12 months with six self-report items: E.g. Behavior ${ }_{\mathrm{BP}}$ "Over the past 12 months, given 10 patients with diabetes whose BP was $5 \mathrm{~mm} \mathrm{Hg}$ above target, for how many did you prescribe an additional antihypertensive drug?" (see Eccles et al. 2011 for all scale items). Self-reported past behavior was also assessed at baseline.

\section{Analyses}

We investigated the correlations between constructs within each theory for each behavior. The performance of the models in explaining variance in the primary outcome of 12 month self-reported behavior and the secondary outcomes of baseline intention and 
simulated behavior was examined by first calculating regression coefficients using ordinary least squares regression in SPSS. We then investigated whether there was evidence of variability in predictor and outcome variables at the organizational level (i.e., primary care practices) by re-running the models controlling for clustering with random intercept multilevel models using MLwiN 2.22 (Rasbash, Browne, Healy, Cameron, \& Charlton, 2010). We then compared the pattern of associations between the regressions and the multilevel models. We did not control for baseline past behavior as our theoretical measures were not designed to predict residual change in behavior. Consistent with the respective theories, we treated intention/proximal goals as both dependent and independent variables.

\section{Ethics Committee Review}

The study was approved by Newcastle and North Tyneside Research Ethics Committee Two (REC Ref Number 07/H0907/102).

\section{Results}

\section{Response Rate}

Of the 843 questionnaires sent at baseline, 489 (326 GPs, 163 nurses) were returned completed (58\% baseline response). Baseline questionnaires were returned by at least one clinician from all 99 practices. At follow-up, 427 (289 GPs, 138 nurses) questionnaires were returned ( $87 \%$ follow-up response). The cumulative response rate was $51 \%$.

\section{Descriptive Statistics and Correlations}

Descriptive statistics are presented in Table 1. Ninety-nine percent of nurses and $45 \%$ of GPs were women. The mean year of qualification for GPs was $1986(\mathrm{SD}=8.50)$ whilst for nurses it was $1984(\mathrm{SD}=8.25)$. Internal consistency for all measures are reported in detail in Eccles et al. (2011) and summarized in Supplementary File 2. For constructs measured with at least three items, internal consistency (Cronbach's alpha) across measures ranged from 0.70 to 0.97 ; for 2-item measures, internal consistency (Pearson $r$ ) ranged from 0.32 to 0.81 . 
Clinicians reported engaging in each behavior with most patients, though considerable variability was observed between clinicians within and across behaviors. Mean scores on measures of theoretical constructs exceeded the scale mid-point for all behaviors, indicating a direction favoring the behavior (Eccles et al., 2011).

$<$ Table 1>

Table 2 presents a summary of the range and median correlations for each construct across behaviors (Supplemental File 3 presents detailed correlations). Based on effect size indices for correlation coefficients proposed by Cohen (1992) median associations between theory-based constructs and 12-month self-reported behavior scores were small-to-medium across constructs, with intention/proximal goals and both habit measures demonstrating the strongest correlation with this measure across behaviors (Table 2). Median correlations between theory-based predictors and simulated behavior scores were smaller (Supplemental File 3). The association between 12-month self-reported behavior and simulated behavior scores ranged from $r=-.05$ to $r=.32$ (median $r=.18$ ).

The median correlation between theorized predictors and intention strength was medium-to-large with attitude, outcome expectations, subjective norm and habit showing the highest median association with intention strength. Median associations between theorybased predictors and direct estimation of intention scores were also medium-to-large across behaviors though lower than associations with intention strength (Supplemental File 3). We also observed a large median association between intention strength and direct estimation of intention across behaviors, suggesting that the two intention measures may be measuring similar aspects of intentionality.

$<$ Table 2> 


\section{Predictive Models}

Overall, there was very little difference in predictive patterns when accounting for practice level clustering, suggesting that much of the variability in behavior was located between individual clinicians rather than between practices (Supplemental File 4 presents results accounting for practice-level variance). Given the lack of significant effect of accounting for clustering, results are presented based on ordinary least squares regressions.

\section{Predicting Behavior}

Figure 1 presents the constructs tested within each theory, with the number of behaviors out of six for which each construct was significantly associated with. Table 3 summarizes the amount of variability in 12-month self-reported behavior and simulated behavior accounted for by constructs from each theory.

Overall. Over all behaviors, theories explained a similar amount of variability in follow-up 12 month self-reported behavior, ranging from $R_{\text {adj }}^{2}=.11$ for planning to $R_{\text {adj }}^{2}=.19$ for the TPB. Consistently more variance was explained in 12-month self-reported behavior (median $R_{\text {adj }}^{2}$ range across behaviors $=.11$ to $.19 ;$ median $R_{\text {adj }}^{2}$ range across theories $=.10$ to .47) than simulated behavior (median $R_{\text {adj }}^{2}$ range across behaviors $=.03$ to .07 ; median $R_{\text {adj }}^{2}$ range across theories $=.00$ to .13 ).

By theory. Across all the models the median of the medians for the prediction of selfreported behavior was 0.15 . The TPB (using direct estimation of intention) had the highest model median at 0.19 while SCT had the highest individual behavior value of 0.50 . Prediction of simulated behavior was low across theories, with a median of medians across the models of 0.05 . SCT constructs predicted the greatest amount of variance in simulated behavior across behaviors and also had the highest $R^{2}$ value for an individual behavior at 0.15 for Behavior feet. 
By constructs within theories. For TPB constructs, intention (intention strength and direct estimation of intention) was a significant predictor of all self-reported behaviors, whilst perceived behavioral control predicted only two of the six behaviors - Behavior ${ }_{\text {weight }}$ and

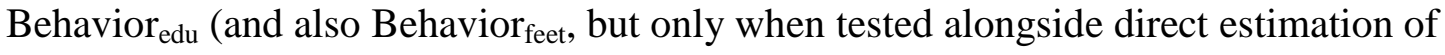
intention). For SCT, proximal goals and self-efficacy predicted all six self-reported behaviors, and outcome expectations predicted one of six behaviors. For Learning Theory, evidence of habit predicted all behaviors, whereas anticipated consequences predicted one behavior $\left(\right.$ Behavior $_{\text {self-man }}$ ). Habit assessed with the self-reported habit index was a significant predictor of all behaviors. Operationalizing habit in Learning Theory using the self-reported habit index showed a similar pattern of results as when operationalized using the two-item evidence of habit scale. Action planning predicted four of the six whilst coping planning predicted five behaviors, and all behaviors were predicted by at least one of the two planning constructs.

By behavior. Prediction of Behavior ${ }_{\text {feet }}$ was consistently high, exhibiting the highest $R^{2}$ for all models. Prediction of self-reported behavior ranged from $R_{\text {adj }}^{2}=.32$ (planning) to $R_{\text {adj }}^{2}=.50(\mathrm{SCT})$, median $R_{\text {adj }}^{2}=.47$, and simulated behavior ranged from and $R_{\text {adj }}^{2}=.05$ (planning) to $R_{\text {adj }}^{2}=.15(\mathrm{SCT})$, median $R_{\text {adj }}^{2}=.13$. The theoretical models predicted considerably less variability in the other behaviors (ranging from median $R_{\text {adj }}^{2}=.10$ for

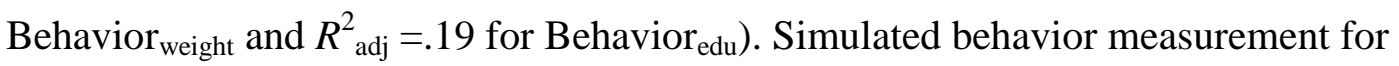
Behavior $_{\mathrm{HbAlc}}$ was poorly predicted by all models.

\author{
$<$ Table 3> \\ $<$ Figure 1>
}

\title{
Predicting Intention
}

Table 4 summarizes the amount of variability in intention strength and direct estimation of intention scores accounted for by constructs from each theory. 
Overall. All models performed better in predicting intention strength (median $R_{\text {adj }}^{2}$ range across behaviors $=.51$ to $.71 ;$ median $R_{\text {adj }}^{2}$ range across theories $=.48$ to .76 ) than direct estimation of intention scores (median $R_{\text {adj }}^{2}$ range across behaviors $=.15$ to .53 ; median $R_{\text {adj }}^{2}$ range across theories $=.27$ to .35 ). The median of the median $R^{2}$ predicting intention strength was 0.66 . and for direct estimation of intention the value was lower at 0.34 .

By theory. Of the individual models, Learning Theory explained the most variance in intention across behaviors and had the highest individual $R^{2}$, explaining $85 \%$ of the variance

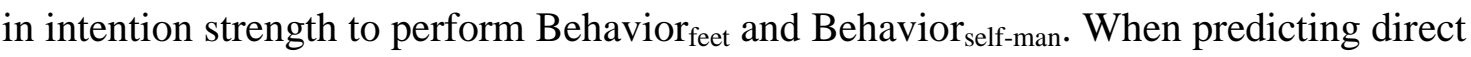
estimation of intention the individual model values were consistently lower. Learning Theory and the TPB both explained a median $35 \%$ of the variance in direct estimation of intention across behaviors; Learning Theory had the highest single $R^{2}$ value of $62 \%$ for Behavior feet. $_{\text {. }}$

By constructs within theories. All TPB predictors of intention predicted intention strength across all six behaviors, though attitude was the only TPB construct that predicted direct estimation of intention across all behaviors. In SCT, self-efficacy and outcome expectations both significantly predicted proximal goals across all behaviors. For Learning Theory, evidence of habit predicted variance in scores on both intention measures across all behaviors, whereas anticipated consequences accounted for variance in intention for two of the behaviors (Behavior ${ }_{\text {weight }}$ and Behavior $_{\mathrm{BP}}$ ). Scores on the self-reported habit index accounted for significant variance in scores for both intention measures across all behaviors.

By behavior. Prediction of intention strength was consistently high, with median $R^{2}$ exceeding 0.50 for all behaviors, with intention for Behavior ${ }_{\mathrm{BP}}$ and Behavior $_{\text {feet }}$ being best predicted. Median $R^{2}$ for direct estimation of intention was highest for Behavior feet $_{\text {and lowest }}$ for Behavior ${ }_{\text {weight. }}$ 
Details of the dependent and independent variables included in all analyses and results of random intercept multilevel models and ordinary least squares multiple regression analyses for all models are presented in Supplemental File 4 and Supplemental File 5 respectively.

$<$ Table 4>

\section{Discussion}

\section{Summary of Findings}

The present study showed that when prospectively testing multiple theories of behavior across six clinician behaviors within one sample of clinicians, considerable variability between behaviors was observed in the mean scores and prediction from theoretical constructs. This is an important finding given that a recent meta-analysis (Godin et al., 2008) suggested that the prediction of clinical behavior from social cognition model constructs varied due to methodological issues including sample size, psychometric quality, level of correspondence between measures and behavior. The design of the present study controlled for these potential sources of variability between behaviors and nevertheless observed considerable variability in the performance of each theory between behaviors, with foot examination being better predicted than providing weight advice and prescribing. We can now move beyond suggesting these methodological moderators as explanations for variability in predictions across studies, and focus on trying to understand why current theoretical models of behavior do not account for why some behaviors are better predicted than others (McEachan, Conner, Taylor, \& Lawton, 2011). More theorizing concerning the moderators and mediators of the relationship between predictors and behaviors is needed to explain the variability in the predictability of the behaviors. The nature of the behaviors themselves may be an effect modifier, but is not a modifiable factor, which leaves little opportunity for behavior change - instead, modifiable determinants should be sought. 


\section{Testing theory in multiple behaviors}

Constructs from each theory consistently predicted all six behaviors, suggesting that this may be generalizable to other clinical behaviors. Indeed, a similar pattern of predictors was observed in the PRIME studies. This is important because it highlights the value of using theoretical models as a summary of current evidence of factors predicting behavior and interrelations, indicating factors which have recognized methods of operationalization, which consistently predict clinician behavior and which can inform intervention design in other clinical behavioral contexts. We have identified constructs that are consistently predictive of behavior in the same clinicians across multiple behaviors, which for the first time provides robust evidence for targeting the same construct to address multiple behaviors.

The present study also demonstrated that across behaviors, mean scores for constructs in some theories tended to be high. With a view to informing intervention design, mean scores and their variability can assist in identifying predictors which have sufficient variability and potential for improvement to be effected by interventions. In the present study, mean scores for all $T P B$ constructs tended to be high across behaviors. This is not a new finding (e.g., Bonetti et al., 2006). Primary care clinicians are clearly highly motivated, have positive attitudes, think others would approve, and feel capable, yet mean scores on self-reported behavior were modest in comparison. This has implications for changing clinician behaviors: at least in diabetes care, targeting motivation may not be effective. Promoting intention is of central importance, but our results suggest that the real challenge lies in helping clinicians to translate their intention into behavior.

Interventions that have changed intentions show that a medium-to-large change in intention scores leads to a small-to-medium change in behavior (Webb \& Sheeran, 2006). Intention scores must necessarily be sufficiently low at baseline for such change to be observed. In the present study, the median intention score across behaviors was 5.65 on a 1 to 
7 scale, suggesting that the scope for improvement may not be sufficient to realize the level of change in intention required to change behavior on average, though it may be valuable for low scoring clinicians. Theories which include targetable direct predictors of behavior besides, or in addition to, intention would be preferred for general non-tailored interventions.

\section{Consistency in theoretical predictors across behaviors}

Scores on self-efficacy within SCT tended to be lower, nearing the mid-point of the scale for some behaviors. While proximal goal and outcome expectation scores were high, future studies based on SCT could target self-efficacy beliefs using the suite of behavior change techniques inherent to SCT (Ashford, Edmunds, \& French, 2010; Bandura, 1986; Hrisos et al., 2008). Similarly, in the context of Learning Theory, while anticipated consequences was not predictive, habit mean scores were consistently relatively low and predicted each behavior. Scores and observed effect sizes for Habit were in line with those reported in a review of the association between self-reported habit, measured with the self-reported habit index, and physical activity and nutrition behavior (Gardner, de Bruijn, \& Lally, 2011). This provides further evidence for the applicability of habit as a predictor of clinical behavior (Bonetti et al., 2010). Notably, our two-item measure performed as well as the 12-item selfreported habit index. Promoting habitual performance is desirable as it maximizes efficiency and Learning Theory suggests how these changes might be achieved and maintained.

While action planning predicted most behaviors, mean scores tended to be high; this appears to be a strategy which clinicians already use. However, coping planning mean scores were consistently among the lowest whilst predicting five of six behaviors. To our knowledge, the present study is the first to report on the relationship between coping planning and clinical behavior. Coping planning interventions may offer a promising option for 
behavior change in this context, as it is a post-intentional, proximal determinant of behavior that can be operationalized as a behavior change technique.

\section{Predicting clinician behaviors}

The median amount of variability in behavior accounted for across behaviors (0.15) was notably lower than the frequency-weighted mean $R^{2}$ of .32 observed in Godin et al's review (2008). There may be at least two reasons for this. Firstly, we reported adjusted $R^{2}$, which controls for the number of constructs included in a given model when estimating variance explained. This may have reduced the size of the $R^{2}$ in the present study relative to the review's pooled estimates. Secondly, the effect sizes reported by Godin et al. may be inflated by constructs that are not part of the respective theoretical models. For example, Bernaix's (2000) test of the Theory of Reasoned Action included attitude, knowledge, ethnicity, and education as final predictors of behavior, none of which are theorized to be direct predictors of behavior in the Theory of Reasoned Action. By remaining true to the theories, the effect sizes reported in the present study of a representative sample of primary care health professionals in the United Kingdom can be considered as more closely reflecting the predictive power of motivation and action theories applied to understand clinician behavior.

One explanation for the observed lower prediction of simulated behavior may involve the correspondence between the predictor variables and simulated behavior. The wording of the 12-month self-report of behavior matched the Target, Action, Context and Time-specification of the predictor variables. For simulated behavior, the target, context and time were much more specific than the self-reported behavior measure, whilst the action itself was less clear and was left to the clinician to specify. This lack of correspondence may have led to lower associations, which were of the order of magnitude observed when predicting objective measures of clinical behavior (Bonetti et al., 2006; Eccles et al., 2007). Another explanation for the lower prediction of simulated behavior may involve scenario framing. Scenarios were 
designed to reflect the multiple behaviors involved in the study but it may be less likely that performing all six would be feasible within the same scenario. The present study contributes to the discussion of behavioral outcome measurement challenges in this context.

To our knowledge, this study is among the first to account for organizational practicelevel variability when testing behavioral theory with health professionals. Results showed that the vast majority of the variation in the outcomes tested was located at the individual rather than the practice level. This has implications for theory. While diabetes care is provided by groups of clinicians within practices, the extent of shared cognitions within practices is limited (Eccles, Hrisos, et al., 2009). Rather, much of the variability is between clinicians within practices. Understanding the behaviors underlying the provision of high quality healthcare seems to require theories which allow an understanding of behavior at the individual level.

In the three PRIME studies with objectively-assessed behavior, perceived behavioral control predicted each behavior. Intention, self-efficacy, action planning and anticipated consequences predicted two behaviors, and evidence of habit and outcome expectations predicted behavior in one of three samples. The pattern was similar for the three PRIME studies which had simulated behavior as a second outcome, with intention, action planning and anticipated consequences predicting all three and perceived behavioral control, outcome expectations, self-efficacy and evidence of habit predicting two. The present study used a self-reported instead of objectively-assessed behavior as the main behavioral outcome and observed largely similar results. The present study showed that intention/proximal goals, selfefficacy and habit predicted all six behaviors in the same sample of clinicians. Action planning predicted four behaviors, and coping planning and outcome expectations predicted five. Perceived behavioral control predicted two behaviors and anticipated consequences predicted only one of six behaviors in the present study. The findings are remarkably similar. 
As a result we have more confidence in the finding that intentional, post-intentional (planning), self-efficacious, and non-intentional (habit) processes are important predictors and likely determinants of the clinician behaviors that result in high quality care.

\section{Construct overlap between theories}

The theories we have investigated have overlapping constructs and this may be addressed as theoretical, measurement or empirical issues. Theoreticians including Bandura and Aizen present reasoned arguments for seeing constructs such as self-efficacy and perceived behavioral control as distinct, or similar, or as perceived behavioral control including self-efficacy. Michie et al. (2005) have addressed this problem by attempting to identify theoretical domains that predict clinician behaviors and the domain of 'beliefs about capabilities' includes both perceived behavioral control and self-efficacy, while the domain of 'beliefs about consequences' includes both attitudes and outcome expectancies. However, by considering constructs separately from their theories, the use of theoretical domains removes the important aspect of theories i.e. how different constructs relate in explaining behavior. We have therefore continued to examine constructs within their theories.

Nevertheless, the overlaps represent a measurement issue and it is not clear that it is possible to measure one construct such as perceived behavioral control without simultaneously measuring another such as self-efficacy. Item aggregation methods such as factor analyses would result in aggregations of items from different theoretical constructs, thus losing the ability to relate to the theories and probably creating new constructs in a field where there are already too many. Factor analysis cannot establish the content validity of the items, only how items relate to other items. In addition, the results would be entirely dependent on the specific items included in our study and this is a matter of content validity rather than empirically established construct validity. Work by Dixon (2006) indicates that standard methods of measuring perceived behavioral control and self-efficacy do not 
distinguish the constructs satisfactorily, except where a compound measure of self-efficacy is used, as recommended by Bandura. There is evidence that constructs distinguished in the theories may have different predictive validity in empirical studies. For example, selfefficacy has been shown to explain unique variance in intention and behavior not accounted for by perceived control in a range of contexts (Hagger, Chatzisarantis, \& Biddle, 2002). Further work needs to be done to establish the distinct content validity of measures of similar constructs.

\section{Strengths}

The present study is among the largest, most representative behavioral theory-based studies of predictors of clinician behavior to date. In 2008, Godin et al. identified 16 prospective tests of social cognition models, highlighting the need for more such designs. The present study tested four theories as predictors of six distinct behaviors, thus contributing 24 more prospective tests of theory to the literature. The study also distinguishes itself by a strong response rate, which is a recognized challenge with this population.

\section{Limitations and Future Studies}

The primary limitation to this study is our inability to link clinicians' responses to an individual clinician level objective measure of their behavior; objective data were only available at an aggregate practice level. We have therefore relied on self-reported behavior which has limitations (e.g., recall bias). While a limitation, there are a number of advantages of self-reported behavior over other measures of behavior, including the specificity with which behavior can be described when measured, the degree of correspondence that can be achieved between the measures of the theoretical constructs and the measure of behavior, and the capacity to link responses at an individual level. These measurement issues have been 
noted by Eccles et al (2009) and reflect a broader issue in the field, as objective data (e.g., from patient medical notes) are often only available at higher levels of aggregation than the clinician and have their own potential limitations. Future research should aim to theorize and test whether responses within practices on constructs from individual-level theories can be aggregated in a theoretically meaningfully way to predict objective measures of clinical behavior that exist only at a practice level (Eccles, Hrisos, et al., 2009).

Another limitation involves the relatively poor psychometric properties of perceived behavioral control. This is not the first study to observe this (Bonetti et al., 2010; Eccles et al., 2007; Grimshaw et al., 2011), and may highlight a need for further development of perceived behavioral control measures. In addition, our measure of anticipated consequences included only items reflecting negative consequences. Future research should consider positive consequences as well.

While habit consistently predicted behavior, one of the two habit measures, the selfreported habit index, has recognized limitations in terms of construct validity, measurement and the lack of reference to contextual cues (Sniehotta \& Presseau, 2012). This study addressed the latter by modifying the stem of the self-reported habit index to be specific to a particular target, action, context and time. Notably, the other more parsimonious two-item habit scale accounted for nearly identical amounts of variability in behavior as the selfreported habit index (Supplemental File 5). While measurement challenges remain, the relationship between non-reflective processes including habit and health professional behavior merit further investigation.

There may be differences between nurses and GPs, as well as other demographic factors, in constructs and behaviors. However, the theories themselves do not provide testable hypotheses for understanding these differences. As diabetes care is a team-based effort involving behaviors crossing traditional roles (e.g., some nurses can prescribe medication), 
the most defensible test of the theories was the one presented, as the variance accounted for reflects only the constructs in the theories. Future studies could hypothesise and test for differences between professional groups. In addition, consistent with recommend best practice we did not control for past behavior as our aim was not to predict residual change in behavior, though this may have implications for the strength of the relationship between habit and behavior that should be explored in future studies.

An open question involves how theories, or their constituent constructs, contribute together in predicting clinician behavior? In PRIME (Bonetti et al., 2010; Eccles et al., 2007; Grimshaw et al., 2011), we have previously added all constructs into a model with the aim of predicting the most amount of variability possible. However, the resulting data-driven model lacks generalizability and the potential to develop a cumulative knowledge base. Further, it does not offer a good basis for developing interventions given the lack of adequate testing of the combined effects of manipulating the constructs. Data-driven models undermine the original strength of constituent theories: the theorized and evidenced relationships between explanatory variables and behavior, including mediating mechanisms. Theoreticians have cautioned against 'cafeteria-style theorizing' i.e. arbitrarily choosing constructs from different theories or using empirically-driven combinations of constructs from various theories (Bandura, 1998). Nevertheless, the results from the present study clearly suggest that there is a need to begin to compare and integrate theories. This should be a theory-driven exercise based on hypothesized relationships between theories and their constructs prior to empirical testing. Such an exercise should consider the conceptual similarities and distinctions between theories and their constructs. A theoretically-driven effort is needed to combine and integrate theory (Noar \& Zimmerman, 2005) which could involve dual processes (Strack \& Deutsch, 2004), competing and facilitating behaviors (Presseau, Francis, Campbell, \& Sniehotta, 2011) and organizational constructs (Eccles et al., 2011). 


\section{Conclusions}

Self-efficacy (SCT), habit (learning theory), and coping planning consistently predicted multiple health professional behaviors, had lower mean scores and higher variation relative to other constructs. These constructs could be targeted for change using wellspecified behavior change techniques (Michie et al., in press). Techniques inherent to SCT such as promoting mastery experiences using graded tasks could be used to increase selfefficacy to perform the behaviors in challenging clinical consultations identified by clinicians. Habit could be targeted by supporting clinicians to use action planning to promote the formation of if-then associations between patient characteristics and pre-planned responses, and by prompting behavioral rehearsal/practice; and coping planning could be targeted by supporting clinicians to engage in problem solving by helping them to identify barriers and supporting them in pre-planning alternatives when such barriers present themselves. Targeting these constructs within their respective theories could inform quality improvement interventions aimed at changing clinician behavior. 


\section{References}

Adler, A. I., Stratton, I. M., Neil, H. A. W., Yudkin, J. S., Matthews, D. R., Cull, C. A., . . Holman, R. R. (2000). Association of systolic blood pressure with macrovascular and microvascular complications of type 2 diabetes (UKPDS 36). BMJ, 321, 412-419.

Ajzen, I. (1991). The theory of planned behavior. Organizational behavior and human decision processes, 50, 179-211.

Ashford, S., Edmunds, J., \& French, D. P. (2010). What is the most effective way to change self-efficacy to promote lifestyle and recreational physical activity? A systematic review with meta-analysis. British Journal of Health Psychology, 15, 265-288.

Bandura, A. (1986). Social foundations of thought and action: A social cognitive theory. Upper Saddle River, NJ: Prentice-Hall.

Bandura, A. (1998). Health promotion from the perspective of social cognitive theory. Psychology \& Health, 13, 623-649.

Bandura, A. (2006). Guide for constructing self-efficacy scales. In F. Pajares \& T. Urdan (Eds.), Self-efficacy beliefs of adolescents (pp. 307-337). Greenwich, CT: Information Age Publishing.

Bernaix, L. W. (2000). Nurses' attitudes, subjective norms, and behavioral intentions toward support of breastfeeding. Journal of Human Lactation, 16, 201-209.

Blackman, D. E. (1974). Operant conditioning: an experimental analysis of behaviour. Cambridge: Mathuen.

Bonetti, D., Johnston, M., Clarkson, J. E., Grimshaw, J., Pitts, N. B., Eccles, M., . . Walker, A. (2010). Applying psychological theories to evidence-based clinical practice: identifying factors predictive of placing preventive fissure sealants. Implementation Science, 5, 25. doi: 10.1186/1748-5908-5-25 
Bonetti, D., Pitts, N. B., Eccles, M. P., Grimshaw, J. M., Johnston, M., Steen, N., . . Walker, A. (2006). Applying psychological theory to evidence-based clinical practice: identifying factors predictive of taking intra-oral radiographs. Social science \& medicine, 63, 1889-1899.

Cohen, J. (1992). A power primer. Psychological Bulletin, 112, 155-159.

Dixon, D. (2006). Conceptual and Measurement Models of Disability. (PhD), University of Aberdeen, $\mathrm{PhD}$ thesis.

Eccles, M. P., Grimshaw, J. M., Johnston, M., Steen, N., Pitts, N. B., Thomas, R., . . . Walker, A. (2007). Applying psychological theories to evidence-based clinical practice: Identifying factors predictive of managing upper respiratory tract infections without antibiotics. Implementation Science, 2:26.

Eccles, M. P., Hawthorne, G., Johnston, M., Hunter, M., Steen, N., Francis, J., . . Grimshaw, J. M. (2009). Improving the delivery of care for patients with diabetes through understanding optimised team work and organisation in primary care. Implementation Science, 4, 22. doi: 10.1186/1748-5908-4-22

Eccles, M. P., Hrisos, S., Francis, J. J., Stamp, E., Johnston, M., Hawthorne, G., . . Hunter, M. (2011). Instrument development, data collection and characteristics of practices, staff and measures in the Improving Quality of Care in Diabetes (iQuaD) Study. Implementation Science, 6, 61. doi: 10.1186/1748-5908-6-61

Eccles, M. P., Hrisos, S., Francis, J. J., Steen, N., Bosch, M., \& Johnston, M. (2009). Can the collective intentions of individual professionals within healthcare teams predict the team's performance: developing methods and theory. Implementation Science, 4, 24.

Fishbein, M. (1967). Attitude and the prediction of behavior. In M. Fishbein (Ed.), Readings in attitude theory and measurement. New York: Wiley. 
Francis, J. J., Eccles, M. P., Johnston, M., Walker, A., Grimshaw, J. M., Foy, R., . . Bonetti, D. (2004). Constructing questionnaires based on the theory of planned behaviour: A manual for health services researchers.

Gardner, B., de Bruijn, G.-J., \& Lally, P. (2011). A systematic review and meta-analysis of applications of the self-report habit index to nutrition and physical activity behaviours. Annals of Behavioral Medicine, 42, 174-187.

Godin, G., Bélanger-Gravel, A., Eccles, M. P., \& Grimshaw, J. M. (2008). Healthcare professionals' intentions and behaviours: A systematic review of studies based on social cognitive theories. Implementation Science, 3, 36.

Grimshaw, J. M., Eccles, M. P., Steen, N., Johnston, M., Pitts, N. B., Glidewell, L., . . Walker, A. (2011). Applying psychological theories to evidence-based clinical practice: identifying factors predictive of lumbar spine $\mathrm{x}$-ray for low back pain in UK primary care practice. Implementation Science, 6, 55.

Grol, R. P. T. M., Bosch, M. C., Hulscher, M. E. J. L., Eccles, M. P., \& Wensing, M. (2007). Planning and studying improvement in patient care: The use of theoretical perspectives. Milbank Quarterly, 85, 93-138. doi: 10.1111/j.1468-0009.2007.00478.x

Hagger, M. S., Chatzisarantis, N. L. D., \& Biddle, S. J. H. (2002). A meta-analytic review of the theories of reasoned action and planned behavior in physical activity: Predictive validity and the contribution of additional variables. Journal of Sport \& Exercise Psychology, 24, 3-32.

Hrisos, S., Eccles, M. P., Johnston, M., Francis, J. J., Kaner, E. F. S., Steen, I. N., \& Grimshaw, J. M. (2008). An intervention modelling experiment to change GPs' intentions to implement evidence-based practice: Using theory-based interventions to promote GP management of upper respiratory tract infection without prescribing antibiotics. BMC HSR, 8:10, . 
HSCIC. (2012). National Diabetes Audit 2010-2011 Report 1: Care Processes and Treatment Targets.

McEachan, R. R. C., Conner, M., Taylor, N., \& Lawton, R. J. (2011). Prospective prediction of health-related behaviors with the Theory of Planned Behavior: A meta-analysis. Health Psychology Review, 5, 97-144. doi: 10.1080/17437199.2010.521684

Michie, S., Johnston, M., Abraham, C., Lawton, R., Parker, D., \& Walker, A. (2005). Making psychological theory useful for implementing evidence based practice: a consensus approach. Quality \& Safety in Health Care, 14, 26-33.

Michie, S., Johnston, M., Francis, J. J., Hardeman, W., \& Eccles, M. P. (2008). From theory to intervention: Mapping theoretically derived behavioural determinants to behaviour change techniques. Applied Psychology: An International Review, 57, 660-680.

Michie, S., Richardson, M., Johnston, M., Abraham, C., Francis, J., Hardeman, W., . . Wood, C. E. (in press). The behavior change technique taxonomy (v1) of 93 hierarchically clustered techniques: Building an international consensus for the reporting of behavior change interventions. Annals of Behavioral Medicine. doi: $10.1007 / \mathrm{s} 12160-013-9486-6$

National Institute for Health and Clinical Excellence. (2008). Type 2 diabetes: the management of type 2 diabetes (update). London: Royal College of Physicians.

NHS_Information_Centre. (2010). Practice level QOF tables 2009/10 - prevalence. Retrieved from: http://www.ic.nhs.uk/webfiles/QOF/200910/Prevalence\%20tables/QOF0910_Pracs_Prevalence_Aug_2011.xls

Noar, S. M., \& Zimmerman, R. S. (2005). Health Behavior Theory and cumulative knowledge regarding health behaviors: Are we moving in the right direction? Health Education Research, 20, 275-290. 
Presseau, J., Francis, J. J., Campbell, N. C., \& Sniehotta, F. F. (2011). Goal conflict, goal facilitation, and health professionals' provision of physical activity advice in primary care: An exploratory prospective study. Implementation Science, 6, 73.

Rasbash, J., Browne, W. J., Healy, M., Cameron, B., \& Charlton, C. (2010). MLwiN (Vol. 2.20). Bristol, UK.

Sniehotta, F. F., \& Presseau, J. (2012). The habitual use of the self-report habit index. Annals of Behavioral Medicine, 43, 139-140.

Sniehotta, F. F., Schwarzer, R., Scholz, U., \& Shuz, B. (2005). Action planning and coping planning for long-term lifestyle change: Theory and assessment. European Journal of Social Psychology, 35, 565-576.

Strack, F., \& Deutsch, R. (2004). Reflective and Impulsive Determinants of Social Behavior. Personality and Social Psychology Review, 8, 220-247.

Verplanken, B., \& Orbell, S. (2003). Reflections on past behavior: A self-report index of habit strength. Journal of Applied Social Psychology, 33, 1313-1330.

Walker, A. E., Grimshaw, J., Johnston, M., Pitts, N., Steen, N., \& Eccles, M. (2003). PRIME - PRocess modelling in ImpleMEntation research: selecting a theoretical basis for interventions to change clinical practice. BMC Health Services Research, 3, 22.

Webb, T. L., \& Sheeran, P. (2006). Does Changing Behavioral Intentions Engender Behavior Change? A Meta-Analysis of the Experimental Evidence. Psychological Bulletin, 132, 249-268. 
Table 1 Descriptive statistics for scores on theoretical constructs and behaviors, for six clinical behaviors

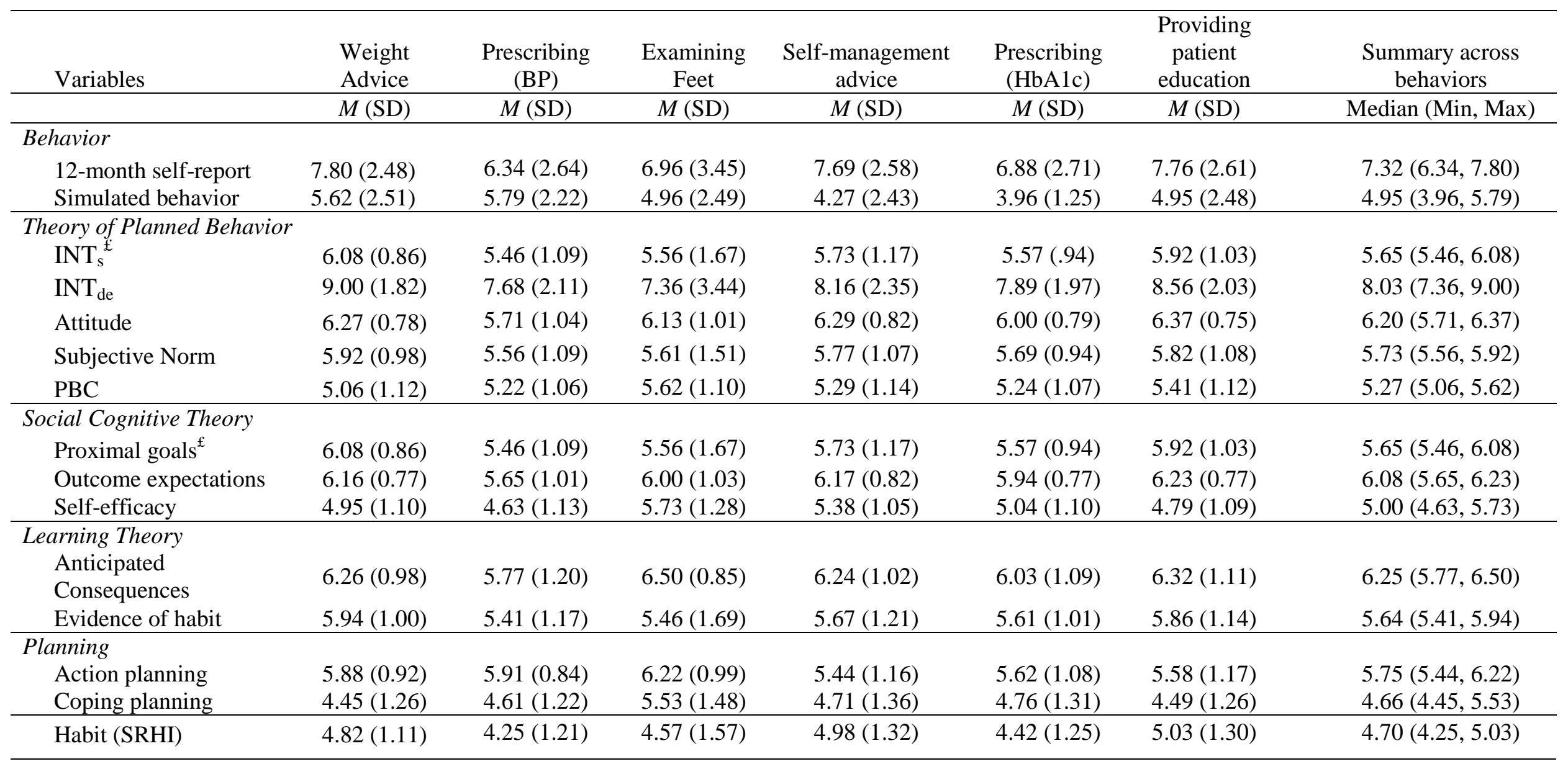

Note. $\mathrm{INT}_{\mathrm{s}}=$ intention strength; $\mathrm{INT}_{\mathrm{de}}=$ direct estimation of intention; $\mathrm{PBC}=$ Perceived behavioral control; $\mathrm{BP}=$ prescribing additional antihypertensive drugs. All theoretical constructs on 7-point scales, except Direct estimation of intention, which is out of 10. 12-m self-report out of 10 . Behavior simulation out of $8 .{ }^{\mathfrak{E}}$ same measures used. SRHI $=$ Self-report Habit Index 
Table 2 Correlations between theoretical predictors and intention (strength) and self-reported behavior, for six clinical behaviors

\begin{tabular}{|c|c|c|c|c|c|c|c|c|c|c|c|c|c|c|}
\hline \multirow[t]{2}{*}{ Variables } & \multicolumn{2}{|c|}{$\begin{array}{l}\text { Weight } \\
\text { Advice }\end{array}$} & \multicolumn{2}{|c|}{$\begin{array}{l}\text { Prescribing } \\
\text { (BP) }\end{array}$} & \multicolumn{2}{|c|}{$\begin{array}{l}\text { Examining } \\
\text { Feet }\end{array}$} & \multicolumn{2}{|c|}{$\begin{array}{c}\text { Self- } \\
\text { managemen } \\
\mathrm{t} \text { advice }\end{array}$} & \multicolumn{2}{|c|}{$\begin{array}{l}\text { Prescribing } \\
\text { (HbA1c) }\end{array}$} & \multicolumn{2}{|c|}{$\begin{array}{l}\text { Providing } \\
\text { patient } \\
\text { education }\end{array}$} & \multicolumn{2}{|c|}{$\begin{array}{c}\text { Summary } r \text { across } \\
\text { behaviors (min, max) }\end{array}$} \\
\hline & $\begin{array}{c}r \\
\mathrm{INT}_{\mathrm{s}}\end{array}$ & $\begin{array}{c}r \\
12 \mathrm{~m} \\
\end{array}$ & $\begin{array}{c}r \\
\mathrm{INT}_{\mathrm{S}}\end{array}$ & $\begin{array}{c}r \\
12 \mathrm{~m}\end{array}$ & $\begin{array}{c}r \\
\mathrm{INT}_{\mathrm{S}}\end{array}$ & $\begin{array}{c}r \\
12 \mathrm{~m}\end{array}$ & $\begin{array}{c}r \\
\mathrm{INT}_{\mathrm{S}}\end{array}$ & $\begin{array}{c}r \\
12 \mathrm{~m}\end{array}$ & $\begin{array}{c}r \\
\mathrm{INT}_{\mathrm{s}}\end{array}$ & $\begin{array}{c}r \\
12 \mathrm{~m}\end{array}$ & $\begin{array}{c}r \\
\mathrm{INT}_{\mathrm{s}}\end{array}$ & $\begin{array}{c}r \\
12 \mathrm{~m}\end{array}$ & $\begin{array}{l}\text { Median } r \\
\text { INT }_{\mathrm{s}}\end{array}$ & $\begin{array}{l}\text { Median } r \\
12 \mathrm{~m}\end{array}$ \\
\hline $\begin{array}{l}\text { Behavior } \\
\text { 12-month self-report } \\
\text { Simulated Behavior } \\
\end{array}$ & $\begin{array}{l}.28^{* *} \\
.17^{* *} \\
\end{array}$ &.$-4^{* *}$ & $\begin{array}{l}.33^{* *} \\
.22^{* *}\end{array}$ &.$-4^{* *}$ & $\begin{array}{l}.69^{* *} \\
.37^{* *}\end{array}$ &.-- & $\begin{array}{l}.41^{* *} \\
.24^{* *}\end{array}$ & $.22^{* *}$ & $\begin{array}{l}.30^{* *} \\
.10\end{array}$ & -- & $\begin{array}{l}.43^{* *} \\
.24^{* *}\end{array}$ & $.24^{* *}$ & & $\begin{array}{c}-- \\
.18(-.05, .32) \\
\end{array}$ \\
\hline $\begin{array}{l}\text { Theory of Planned Be } \\
\mathrm{INT}_{\mathrm{s}} \mathrm{E} \\
\mathrm{INT}_{\mathrm{de}} \\
\text { Attitude } \\
\text { Subjective Norm } \\
\text { PBC }\end{array}$ & $\begin{array}{l}\text { avior } \\
-- \\
.43^{* *} \\
.62^{* *} \\
.60^{* *} \\
.48^{* *}\end{array}$ & $\begin{array}{l}.28^{* * *} \\
.37^{* *} \\
.19^{* *} \\
.19^{* * *} \\
.25^{* *}\end{array}$ & $\begin{array}{l}-- \\
.64^{* *} \\
.82^{* *} \\
.76^{* *} \\
.45^{* *}\end{array}$ & $\begin{array}{l}.33^{* * *} \\
.39^{* *} \\
.29^{* *} \\
.20^{* *} \\
.18^{* *}\end{array}$ & $\begin{array}{l}-- \\
.85^{* *} \\
.70^{* *} \\
.83^{* *} \\
.43^{* *}\end{array}$ & $\begin{array}{l}.69^{* * *} \\
.67^{* *} \\
.42^{* *} \\
.53^{* *} \\
.41^{* *}\end{array}$ & $\begin{array}{l}-- \\
.70^{* *} \\
.71^{* *} \\
.74^{* *} \\
.69^{* *}\end{array}$ & $\begin{array}{l}.41^{* *} \\
.42^{* *} \\
.27^{* *} \\
.30^{* *} \\
.33^{* *}\end{array}$ & $\begin{array}{l}-- \\
.53^{* *} \\
.72^{* *} \\
.71^{* *} \\
.47^{* *}\end{array}$ & $\begin{array}{l}.30^{* *} \\
.44^{* *} \\
.24^{* *} \\
.22^{* *} \\
.23^{* *}\end{array}$ & $\begin{array}{l}-- \\
.63^{* *} \\
.67^{* *} \\
.70^{* *} \\
.67^{* *}\end{array}$ & $\begin{array}{l}.43^{* * *} \\
.54^{* *} \\
.29^{* *} \\
.25^{* *} \\
.37^{* *}\end{array}$ & $\begin{array}{c}-- \\
.64(.43, .85) \\
.71(.62, .82) \\
.73(.60, .83) \\
.48(.43, .69) \\
\end{array}$ & $\begin{array}{l}.37(.28, .69) \\
.43(.37, .67) \\
.28(.19, .42) \\
.24(.19, .53) \\
.29(.18, .41) \\
\end{array}$ \\
\hline $\begin{array}{l}\text { Social Cognitive The } \\
\text { Proximal goals } \\
\text { Outcome } \\
\text { expectations } \\
\text { Self-efficacy }\end{array}$ & $\begin{array}{l}-- \\
.66^{* *} \\
.51^{* *}\end{array}$ & $\begin{array}{l}.28^{* * *} \\
.21^{* * *} \\
.26^{* * *}\end{array}$ & $\begin{array}{l}.85^{* *} \\
46^{* *}\end{array}$ & $\begin{array}{l}.33^{* *} \\
.28^{* *} \\
.28^{* *}\end{array}$ & $.75^{* *}$ & $\begin{array}{l}.69^{* *} \\
.45^{* *} \\
. * *\end{array}$ & $\begin{array}{l}-- \\
.74^{* *} \\
.61^{* *}\end{array}$ & $\begin{array}{l}.41^{* *} \\
.30^{* *} \\
.36^{* *}\end{array}$ & $.77^{* *}$ & $\begin{array}{l}.30^{* *} \\
.24^{* *}\end{array}$ & $\begin{array}{c}-- \\
.72^{* *} \\
.55^{* *}\end{array}$ & $\begin{array}{l}.43^{* *} \\
.30^{* *}\end{array}$ & $.75(.66, .85)$ & $\begin{array}{l}.37(.28, .69) \\
.29(.21, .45)\end{array}$ \\
\hline $\begin{array}{l}\text { Learning Theory } \\
\text { Anticipated } \\
\text { Consequences } \\
\text { Evidence of Habit }\end{array}$ & $\begin{array}{l}.31^{* *} \\
.79^{* * *}\end{array}$ & $\begin{array}{l}.15^{* *} \\
.33^{* *}\end{array}$ & $.42^{* *}$ & $\begin{array}{l}.16^{* *} \\
.26^{* *}\end{array}$ & $\begin{array}{l}.18^{* *} \\
.92^{* *}\end{array}$ & $\begin{array}{l}.15^{*} \\
.66^{* *}\end{array}$ & $\begin{array}{l}.25^{* *} \\
.92^{* *}\end{array}$ & $\begin{array}{l}.22^{* *} \\
.43^{* *}\end{array}$ & $\begin{array}{l}.24^{* *} \\
.84^{* *}\end{array}$ & $\begin{array}{l}.16^{* *} \\
.33^{* *}\end{array}$ & $\begin{array}{l}.18^{*} \\
.90^{* *}\end{array}$ & $\begin{array}{l}.13^{*} \\
.47^{* *}\end{array}$ & $.25(.18, .42)$ & $.16(.13, .22)$ \\
\hline $\begin{array}{l}\text { Planning } \\
\text { Action planning } \\
\text { Coping planning }\end{array}$ & $\begin{array}{l}-- \\
--\end{array}$ & $.14^{* * *}$ & $\begin{array}{l}-- \\
--\end{array}$ & $\begin{array}{l}.24^{* *} \\
.19^{* *}\end{array}$ & $\begin{array}{l}-- \\
--\end{array}$ & $.47^{* *}$ & $\begin{array}{l}-- \\
--\end{array}$ & $\begin{array}{l}.29^{* *} \\
.37^{* *}\end{array}$ & $\begin{array}{l}-- \\
--\end{array}$ & $\begin{array}{l}.26^{* *} \\
.26^{* *}\end{array}$ & $\begin{array}{l}-- \\
--\end{array}$ & $\begin{array}{l}.43^{* * *} \\
.34^{* *}\end{array}$ & $\begin{array}{l}-- \\
--\end{array}$ & $\begin{array}{l}.28(.14, .47) \\
.31(.19, .55)\end{array}$ \\
\hline Habit (SRHI) & $.57^{* *}$ & $.38^{* *}$ & $.66^{* *}$ & $.37^{* * *}$ & $.81^{* *}$ & $.68^{* *}$ & $.76^{* *}$ & $.42^{* *}$ & $.55^{* *}$ & $.34^{* * *}$ & $.73^{* *}$ & $.37^{* *}$ & $.70(.55, .81)$ & $.38(.34, .68)$ \\
\hline
\end{tabular}

Note. $\mathrm{INT}_{\mathrm{s}}=$ intention strength; $\mathrm{INT}_{\mathrm{de}}=$ direct estimation of intention; $12 \mathrm{~m}=12$ month self-reported behavior; $\mathrm{PBC}=\mathrm{Perceived}$ behavioral control; $\mathrm{BP}=$ prescribing additional antihypertensive drugs; SRHI $=$ Self-report Habit Index. $* * p<.01 ; * p<.05,{ }^{\mathfrak{f}}$ same measures used. 
Table 3 Variance in behavior scores explained by constructs from each theory, by behavior

\begin{tabular}{|c|c|c|c|c|c|c|c|c|c|c|c|c|}
\hline \multirow[b]{3}{*}{ Theory } & \multicolumn{12}{|c|}{ Adjusted $R^{2}$} \\
\hline & \multicolumn{2}{|c|}{$\begin{array}{l}\text { Weight } \\
\text { Advice }\end{array}$} & \multicolumn{2}{|c|}{$\begin{array}{l}\text { Prescribing } \\
\text { (BP) }\end{array}$} & \multicolumn{2}{|c|}{$\begin{array}{c}\text { Examining } \\
\text { Feet }\end{array}$} & \multicolumn{2}{|c|}{$\begin{array}{c}\text { Self- } \\
\text { management } \\
\text { advice }\end{array}$} & \multicolumn{2}{|c|}{$\begin{array}{c}\text { Prescribing } \\
(\mathrm{HbA} 1 \mathrm{c})\end{array}$} & \multicolumn{2}{|c|}{$\begin{array}{l}\text { Providing } \\
\text { patient } \\
\text { education }\end{array}$} \\
\hline & $12 \mathrm{~m}$ & Sim & $12 \mathrm{~m}$ & Sim & $12 \mathrm{~m}$ & Sim & $12 \mathrm{~m}$ & Sim & $12 \mathrm{~m}$ & Sim & $12 \mathrm{~m}$ & Sim \\
\hline TPB v1 & 0.09 & 0.03 & 0.10 & 0.05 & 0.48 & 0.13 & 0.17 & 0.06 & 0.09 & 0.00 & 0.19 & 0.06 \\
\hline TPB v2 & 0.17 & 0.03 & 0.15 & 0.02 & 0.49 & 0.11 & 0.19 & 0.09 & 0.19 & -0.01 & 0.32 & 0.07 \\
\hline SCT & 0.09 & 0.07 & 0.12 & 0.05 & 0.50 & 0.15 & 0.18 & 0.07 & 0.10 & 0.00 & 0.19 & 0.06 \\
\hline LT & 0.11 & 0.03 & 0.07 & 0.02 & 0.43 & 0.14 & 0.19 & 0.04 & 0.11 & 0.00 & 0.22 & 0.05 \\
\hline SRHI & 0.14 & 0.01 & 0.14 & 0.02 & 0.46 & 0.13 & 0.17 & 0.05 & 0.11 & 0.00 & 0.13 & 0.04 \\
\hline Planning & 0.07 & 0.04 & 0.06 & 0.00 & 0.32 & 0.05 & 0.14 & 0.03 & 0.08 & 0.00 & 0.19 & 0.04 \\
\hline
\end{tabular}

Note. $12 \mathrm{~m}$ = self-reported behavior at 12 month follow-up; Sim = simulated behavior measured at baseline; TPB v1 =

Theory of Planned Behavior with intention strength; TPB v2 = Theory of Planned Behavior with direct estimation of intention; SCT = Social Cognitive Theory; LT = Learning Theory. SRHI = Self-report Habit Index 
Table 4 Variance in intention scores explained by constructs from each theory, by behavior

\begin{tabular}{|c|c|c|c|c|c|c|c|c|c|c|c|c|}
\hline \multirow[b]{3}{*}{ Theory } & & & \multicolumn{10}{|c|}{ Adjusted $R^{2}$} \\
\hline & \multicolumn{2}{|c|}{$\begin{array}{l}\text { Weight } \\
\text { Advice }\end{array}$} & \multicolumn{2}{|c|}{$\begin{array}{l}\text { Prescribing } \\
\text { (BP) }\end{array}$} & \multicolumn{2}{|c|}{ Examining Feet } & \multicolumn{2}{|c|}{$\begin{array}{l}\text { Self-management } \\
\text { advice }\end{array}$} & \multicolumn{2}{|c|}{$\begin{array}{c}\text { Prescribing } \\
(\mathrm{HbA} 1 \mathrm{c})\end{array}$} & \multicolumn{2}{|c|}{$\begin{array}{c}\text { Providing patient } \\
\text { education }\end{array}$} \\
\hline & $\mathrm{INT}_{\mathrm{s}}$ & $\mathrm{INT}_{\mathrm{de}}$ & $\mathrm{INT}_{\mathrm{s}}$ & $\mathrm{INT}_{\mathrm{de}}$ & $\mathrm{INT}_{\mathrm{s}}$ & $\mathrm{INT}_{\mathrm{de}}$ & $\mathrm{INT}_{\mathrm{s}}$ & $\mathrm{INT}_{\mathrm{de}}$ & $\mathrm{INT}_{\mathrm{s}}$ & $\mathrm{INT}_{\mathrm{de}}$ & $\mathrm{INT}_{\mathrm{s}}$ & $\mathrm{INT}_{\mathrm{de}}$ \\
\hline ТPB & 0.52 & 0.13 & 0.75 & 0.40 & 0.73 & 0.50 & 0.72 & 0.37 & 0.65 & 0.24 & 0.70 & 0.33 \\
\hline SCT & 0.49 & 0.16 & 0.73 & 0.42 & 0.58 & 0.37 & 0.62 & 0.34 & 0.60 & 0.25 & 0.59 & 0.30 \\
\hline $\mathrm{LT}$ & 0.63 & 0.23 & 0.69 & 0.33 & 0.85 & 0.62 & 0.85 & 0.44 & 0.71 & 0.23 & 0.81 & 0.37 \\
\hline SRHI & 0.32 & 0.14 & 0.43 & 0.25 & 0.67 & 0.55 & 0.57 & 0.39 & 0.30 & 0.19 & 0.52 & 0.28 \\
\hline
\end{tabular}

Note. $\mathrm{INT}_{\mathrm{s}}=$ intention strength; $\mathrm{INT}_{\mathrm{de}}=$ direct estimation of intention; TPB = Theory of Planned Behavior; SCT = Social Cognitive Theory; LT = Learning Theory; SRHI = Self-report Habit Index 
Theory of Planned Behaviour across Six Behaviors

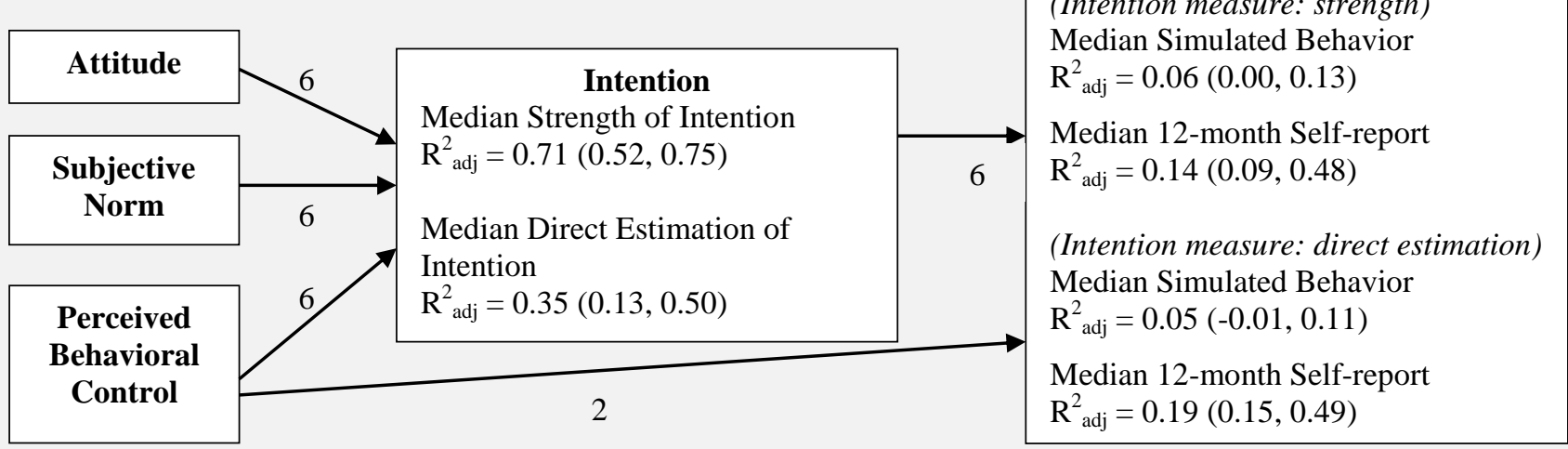

Social Cognitive Theory across Six Behaviors

\begin{tabular}{|c|c|c|c|}
\hline $\begin{array}{c}\text { Outcome } \\
\text { Expectations }\end{array}$ & $\begin{array}{c}\text { Proximal Goals } \\
\text { Median Strength of Intention }\end{array}$ & & $\begin{array}{l}\text { Behavior } \\
\text { Median Simulated Behavior } \\
\mathrm{R}_{\text {adj }}^{2}=0.07(0.00,0.15)\end{array}$ \\
\hline & $\begin{array}{l}\text { Median Direct Estimation of } \\
\text { Intention } \\
\mathrm{R}_{\text {adj }}^{2}=0.32(0.16,0.42)\end{array}$ & 6 & $\begin{array}{l}\text { Median 12-month Self-report } \\
\mathrm{R}_{\text {adj }}^{2}=0.15(0.09,0.50)\end{array}$ \\
\hline
\end{tabular}

Learning Theory across Six Behaviors 1

\begin{tabular}{|c|c|c|}
\hline $\begin{array}{c}\text { Anticipated } \\
\text { Consequences }\end{array}$ & \multicolumn{1}{c|}{$\begin{array}{c}\text { Intention } \\
\text { Evidence of } \\
\text { Habit }\end{array}$}
\end{tabular}

\section{Habit (Self-reported Habit Index) across Six Behaviors}

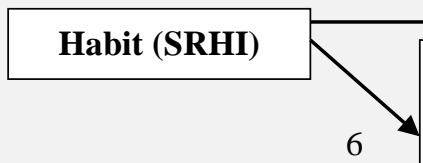

\section{Intention}

Median Strength of Intention

$\mathrm{R}_{\text {adj }}^{2}=0.48(0.30,0.67)$

Median Direct Estimation of Intention

$\mathrm{R}_{\text {adj }}^{2}=0.27(0.14,0.55)$
6

Behavior

Median Simulated Behavior

$\mathrm{R}_{\text {adj }}^{2}=0.03(0.00,0.13)$

Median 12-month Self-report $\mathrm{R}_{\text {adj }}^{2}=0.14(0.11,0.46)$
Planning across Six Behaviors

\begin{tabular}{|c|c|}
\cline { 1 - 1 } Action Planning & \\
\cline { 1 - 1 } Coping Planning & 4 \\
\cline { 1 - 2 } & 5 \\
\hline
\end{tabular}

\section{Behavior}

Median Simulated Behavior $\mathrm{R}_{\text {adj }}^{2}=0.04(0.00,0.05)$

Median 12-month Self-report $\mathrm{R}_{\text {adj }}^{2}=0.11(0.06,0.32)$

Figure 1. Median (range) of $\mathrm{R}_{\text {adj }}^{2}$ across six clinician behaviours, by theory tested. The number above each arrow indicates the number of behaviors (out of 6) for which the relationship is statistically significant $(p<.05)$, when tested against strength of intention and $12 \mathrm{~m}$ self-reported behavior as dependent variables 


\section{Supplemental Tables (Online Supplementary Materials)}

Supplemental File 1: Flowchart of full study

Supplemental File 2: Example of items for each theoretical construct

Supplemental File 3: Bivariate associations within theories for each behavior

Supplemental File 4: Multilevel models predicting intention and behavior, accounting for clustering within practices

Supplemental File 5: Detailed results of standard multiple regression analyses 
Supplemental File 1 - Flowchart of full study

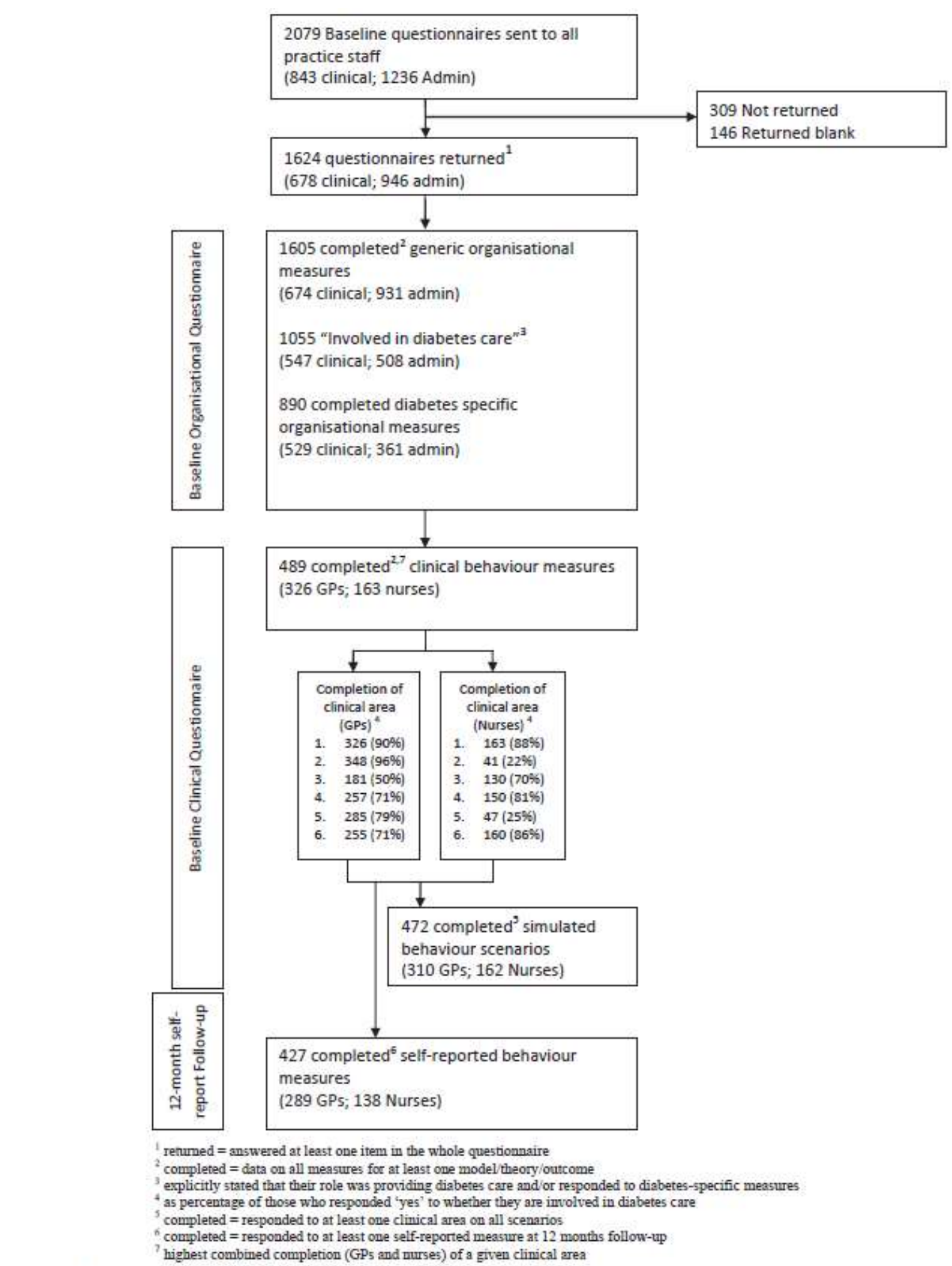

Figure 2 Flowchart of individual clinicians and administrative staff from the 99 practices recruited to the iQuaD study.

This was originally published by BioMed Central in the following paper: Eccles, M.P., Hrisos, S., Francis, J.J, Stamp, E., Johnston, M., Hawthorne, G., Steen, N., Grimshaw, J.M., Elovainio, M., Presseau, J., and Hunter, M. (2011). Instrument development, data collection and characteristics of practices, staff and measures in the Improving Quality of Care in Diabetes (iQuaD) Study. Implementation Science, 6: 61. http://www.implementationscience.com/content/6/1/61 
Supplemental File 2 - Example of items for each theoretical construct

\begin{tabular}{|c|c|c|}
\hline Theory & Construct & Example item and internal consistency \\
\hline \multirow{5}{*}{$\begin{array}{l}\text { Theory } \\
\text { of } \\
\text { Planned } \\
\text { Behavior }\end{array}$} & $\begin{array}{l}\text { Intention (Strength of } \\
\text { agreement) }\end{array}$ & I intend to (Action) (3 items; $\alpha$ range 0.87 to 0.97 ) \\
\hline & $\begin{array}{l}\text { Intention (direct } \\
\text { estimation) }\end{array}$ & $\begin{array}{l}\text { Over the next } 12 \text { months, given } 10 \text { patients (Target), for } \\
\text { how many to do intend to (Action) (single item per } \\
\text { behavior) }\end{array}$ \\
\hline & Attitude & $\begin{array}{l}\text { I think it is good practice to (Action) ( } 3 \text { items; } \alpha \text { range } 0.70 \\
\text { to } 0.93 \text { ) }\end{array}$ \\
\hline & Subjective norm & $\begin{array}{l}\text { Most people whose opinion I value would approve if I } \\
\text { (Action) ( } 2 \text { items; } r \text { range } 0.42 \text { to } 0.69 \text { ) }\end{array}$ \\
\hline & $\begin{array}{l}\text { Perceived behavioral } \\
\text { control }\end{array}$ & $\begin{array}{l}\text { I am confident that I can (Action) ( } 2 \text { items; } r \text { range } 0.32 \text { to } \\
0.50)\end{array}$ \\
\hline \multirow{3}{*}{$\begin{array}{l}\text { Social } \\
\text { Cognitive } \\
\text { Theory }\end{array}$} & Self-efficacy & $\begin{array}{l}\text { I am confident that I can (Action) to (Target), even when } \\
\text { (potential obstacle, e.g., the patient is on seven other } \\
\text { drugs) ( } 4-11 \text { items; } \alpha \text { range } 0.90 \text { to } 0.92 \text { ) }\end{array}$ \\
\hline & $\begin{array}{l}\text { Outcome } \\
\text { expectations }\end{array}$ & $\begin{array}{l}\text { I think it is beneficial to them to (Action) ( } 3 \text { items; } \alpha \text { range } \\
0.74 \text { to } 0.92 \text { ) }\end{array}$ \\
\hline & Proximal goals & I intend to (Action) ( 3 items; $\alpha$ range 0.87 to 0.87 ) \\
\hline \multirow{2}{*}{$\begin{array}{l}\text { Learning } \\
\text { Theory }\end{array}$} & $\begin{array}{l}\text { Anticipated } \\
\text { consequences }\end{array}$ & $\begin{array}{l}\text { On balance, the consequences for me as a GP/Nurse (e.g., } \\
\text { stress, time, future consultations, etc) will be worse in the } \\
\text { long run if I (Action) ( } 2 \text { items; } r \text { range } 0.37 \text { to } 0.57 \text { ) }\end{array}$ \\
\hline & $\begin{array}{l}\text { Habit (evidence of } \\
\text { habit) }\end{array}$ & $\begin{array}{l}\text { I always consider (doing Action) and It is my usual } \\
\text { practice to (Action) ( } 2 \text { items; } r \text { range } 0.50 \text { to } 0.81 \text { ) }\end{array}$ \\
\hline \multirow[b]{2}{*}{ Planning } & Action planning & $\begin{array}{l}\text { I have a clear plan of how I will (Action) (3-4 items; } \alpha \\
\text { range } 0.92 \text { to } 0.97)\end{array}$ \\
\hline & Coping planning & $\begin{array}{l}\text { I have made a clear plan regarding how to (Action) if } \\
\text { (potential obstacle, e.g., the patient is on seven other drugs) } \\
\text { (4-11 items; } \alpha \text { range } 0.95 \text { to } 0.97)\end{array}$ \\
\hline Habit & $\begin{array}{l}\text { Habit (self- } \\
\text { reported } \\
\text { habit index) }\end{array}$ & $\begin{array}{l}\text { (Action) is something I do frequently (12 items; } \alpha \text { range } \\
0.93 \text { to } 0.96 \text { ) }\end{array}$ \\
\hline $\mathrm{n} / \mathrm{a}$ & $\begin{array}{l}\text { 12-month self- } \\
\text { reported behavior }\end{array}$ & $\begin{array}{l}\text { Over the past } 12 \text { months, for approximately how many of } \\
\text { the last } 10 \text { patients (Target) did you (Action) }\end{array}$ \\
\hline
\end{tabular}

Note. Internal consistency was computed using Cronbach's alpha for measures with at least 3 items, and Pearson correlations $(r)$ were used for 2-item measures. Items for proximal goals (SCT) and intention strength (TPB) were the same. 
Supplemental File 3 - Bivariate associations within theories for each behavior

Supplemental Table 3.1

Theory of Planned Behavior Bivariate Associations by Behavior

\begin{tabular}{|c|c|c|c|c|c|c|c|}
\hline Behavior & Variable & 1 & 2 & 3 & 4 & 5 & 6 \\
\hline \multirow{7}{*}{$\begin{array}{l}\text { Providing weight } \\
\text { advice }\end{array}$} & 1. Behavior (12 month self-report) & & & & & & \\
\hline & 2. Behavior (baseline simulation) & $.14^{* *}$ & & & & & \\
\hline & 3. Intention (strength) & $.28^{* *}$ & $.17^{* *}$ & & & & \\
\hline & 4. Intention (direct estimation) & $.37^{* *}$ & $.15^{* *}$ & $.43^{* *}$ & & & \\
\hline & 5. Attitude & $.19^{* *}$ & $.24^{* *}$ & $.62^{* *}$ & $.35^{* *}$ & & \\
\hline & 6. Subjective Norm & $.19^{* *}$ & $.14^{* *}$ & $.60^{* *}$ & $.28^{* *}$ & $.56^{* *}$ & \\
\hline & 7. Perceived Behavioral Control & $.25^{* *}$ & $.13^{* *}$ & $.48^{* * *}$ & $.21^{* *}$ & $.42^{* * *}$ & $.35^{* *}$ \\
\hline \multirow{7}{*}{$\begin{array}{l}\text { Prescribing } \\
\text { additional } \\
\text { antihypertensive } \\
\text { drugs }\end{array}$} & 1. Behavior (12 month self-report) & & & & & & \\
\hline & 2. Behavior (baseline simulation) & $.14^{* *}$ & & & & & \\
\hline & 3. Intention (strength) & $.33^{* *}$ & $.22^{* *}$ & & & & \\
\hline & 4. Intention (direct estimation) & $.39^{* *}$ & $.12^{*}$ & $.64^{* *}$ & & & \\
\hline & 5. Attitude & $.29^{* *}$ & $.18^{* *}$ & $.82^{* *}$ & $.63^{* *}$ & & \\
\hline & 6. Subjective Norm & $.20^{* *}$ & $.18^{* *}$ & $.76^{* *}$ & $.50^{* *}$ & $.72^{* *}$ & \\
\hline & 7. Perceived Behavioral Control & $.18^{* *}$ & $.13^{* *}$ & $.45^{* *}$ & $.29^{* *}$ & $.36^{* *}$ & $.35^{* *}$ \\
\hline \multirow{7}{*}{$\begin{array}{l}\text { Examining feet } \\
\text { (circulation) }\end{array}$} & 1. Behavior (12 month self-report) & & & & & & \\
\hline & 2. Behavior (baseline simulation) & $.32^{* *}$ & & & & & \\
\hline & 3. Intention (strength) & $.69^{* *}$ & $.37^{* *}$ & & & & \\
\hline & 4. Intention (direct estimation) & $.67^{* *}$ & $.33^{* *}$ & $.85^{* *}$ & & & \\
\hline & 5. Attitude & $.42^{* *}$ & $.27^{* *}$ & $.70^{* *}$ & $.56^{* *}$ & & \\
\hline & 6. Subjective Norm & $.53^{* *}$ & $.26^{* *}$ & $.83^{* *}$ & $.70^{* *}$ & $.69^{* *}$ & \\
\hline & 7. Perceived Behavioral Control & $.41^{* *}$ & $.20^{* *}$ & $.43^{* *}$ & $.31^{* *}$ & $.41^{* *}$ & $.35^{* *}$ \\
\hline \multirow{7}{*}{$\begin{array}{l}\text { Providing self- } \\
\text { management } \\
\text { advice }\end{array}$} & 1. Behavior (12 month self-report) & & & & & & \\
\hline & 2. Behavior (baseline simulation) & $.22^{* *}$ & & & & & \\
\hline & 3. Intention (strength) & $.41^{* *}$ & $.24^{* *}$ & & & & \\
\hline & 4. Intention (direct estimation) & $.42^{* *}$ & $.30^{* *}$ & $.70^{* *}$ & & & \\
\hline & 5. Attitude & $.27^{* *}$ & $.15^{* *}$ & $.71^{* *}$ & $.51^{* *}$ & & \\
\hline & 6. Subjective Norm & $.30^{* *}$ & $.17^{* *}$ & $.74^{* *}$ & $.51^{* *}$ & $.69^{* *}$ & \\
\hline & 7. Perceived Behavioral Control & $.33^{* *}$ & $.20^{* *}$ & $.69^{* *}$ & $.52^{* *}$ & $.52^{* *}$ & $.50^{* *}$ \\
\hline \multirow{5}{*}{$\begin{array}{l}\text { Prescribing } \\
\text { additional therapy } \\
\text { for managing } \\
\text { glycemic control }\end{array}$} & 1. Behavior (12 month self-report) & & & & & & \\
\hline & 2. Behavior (baseline simulation) & -.05 & & & & & \\
\hline & 3. Intention (strength) & $.30^{* *}$ & .10 & & & & \\
\hline & 4. Intention (direct estimation) & $.44^{* *}$ & .02 & $.53^{* *}$ & & & \\
\hline & 5. Attitude & $.24^{* *}$ & .07 & $.72^{* *}$ & $.47^{* *}$ & & \\
\hline
\end{tabular}




\begin{tabular}{llllllll} 
& 6. Subjective Norm & $.22^{* *}$ & $.13^{*}$ & $.71^{* *}$ & $.41^{* *}$ & $.66^{* *}$ & \\
& 7. Perceived Behavioral Control & $.23^{* *}$ & .01 & $.47^{* *}$ & $.31^{* *}$ & $.42^{* *}$ & $.33^{* *}$ \\
\hline & 1. Behavior (12 month self-report) & & & & & & \\
2. Behavior (baseline simulation) & $.24^{* *}$ & & & & & \\
& 3. Intention (strength) & $.43^{* *}$ & $.24^{* *}$ & & & & \\
Providing general & 4. Intention (direct estimation) & $.54^{* *}$ & $.25^{* *}$ & $.63^{* *}$ & & & \\
education & 5. Attitude & $.29^{* *}$ & $.14^{* *}$ & $.67^{* *}$ & $.52^{* *}$ & & \\
& 6. Subjective Norm & $.25^{* *}$ & $.19^{* *}$ & $.70^{* *}$ & $.45^{* *}$ & $.62^{* *}$ & \\
& 7. Perceived Behavioral Control & $.37^{* *}$ & $.20^{* *}$ & $.67^{* *}$ & $.44^{* *}$ & $.45^{* *}$ & $.41^{* *}$ \\
\hline
\end{tabular}

${ }^{* *} \mathrm{p}<.01 ; * \mathrm{p}<.05$ 
Supplemental Table 3.2

Social Cognitive Theory Bivariate Associations by Behavior

\begin{tabular}{|c|c|c|c|c|c|c|}
\hline Behavior & Variable & 1 & 2 & 3 & 4 & 5 \\
\hline \multirow{6}{*}{$\begin{array}{l}\text { Providing } \\
\text { weight } \\
\text { advice }\end{array}$} & 1. Behavior (12 month self-report) & & & & & \\
\hline & 2. Behavior (baseline simulation) & $.14^{* *}$ & & & & \\
\hline & 3. Proximal Goals & $.28^{* *}$ & $.17^{* *}$ & & & \\
\hline & $\begin{array}{l}\text { 4. Proximal Goals (direct } \\
\text { estimation) }\end{array}$ & $.37^{* *}$ & $.15^{* *}$ & $.43^{* *}$ & & \\
\hline & 5. Outcome Expectations & $.21^{* *}$ & $.22^{* *}$ & $.66^{* * *}$ & $.35^{* *}$ & \\
\hline & 6. Self-efficacy & $.26^{* *}$ & $.25^{* *}$ & $.51^{* *}$ & $.35^{* *}$ & $.47^{* *}$ \\
\hline \multirow{6}{*}{$\begin{array}{l}\text { Prescribing } \\
\text { additional } \\
\text { anti- } \\
\text { hypertensive } \\
\text { drugs }\end{array}$} & 1. Behavior (12 month self-report) & & & & & \\
\hline & 2. Behavior (baseline simulation) & $.14^{* *}$ & & & & \\
\hline & 3. Proximal Goals & $.33^{* *}$ & $.22^{* *}$ & & & \\
\hline & $\begin{array}{l}\text { 4. Proximal Goals (direct } \\
\text { estimation) }\end{array}$ & $.39^{* *}$ & $.12^{*}$ & $.64^{* *}$ & & \\
\hline & 5. Outcome Expectations & $.28^{* *}$ & $.19^{* *}$ & $.85^{* *}$ & $.62^{* *}$ & \\
\hline & 6. Self-efficacy & $.28^{* *}$ & $.18^{* *}$ & $.46^{* *}$ & $.41^{* *}$ & $.40^{* *}$ \\
\hline \multirow{6}{*}{$\begin{array}{l}\text { Examining } \\
\text { feet } \\
\text { (circulation) }\end{array}$} & 1. Behavior (12 month self-report) & & & & & \\
\hline & 2. Behavior (baseline simulation) & $.32^{* *}$ & & & & \\
\hline & 3. Proximal Goals (strength) & $.69^{* *}$ & $.37^{* *}$ & & & \\
\hline & $\begin{array}{l}\text { 4. Proximal Goals (direct } \\
\text { estimation) }\end{array}$ & $.67^{* *}$ & $.33^{* *}$ & $.85^{* *}$ & & \\
\hline & 5. Outcome Expectations & $.45^{* *}$ & $.26^{* *}$ & $.75^{* *}$ & $.59^{* *}$ & \\
\hline & 6. Self-efficacy & $.51^{* *}$ & $.31^{* *}$ & $.50^{* *}$ & $.42^{* *}$ & $.47^{* *}$ \\
\hline \multirow{6}{*}{$\begin{array}{l}\text { Providing } \\
\text { self- } \\
\text { management } \\
\text { advice }\end{array}$} & 1. Behavior (12 month self-report) & & & & & \\
\hline & 2. Behavior (baseline simulation) & $.22^{* *}$ & & & & \\
\hline & 3. Proximal Goals & $.41^{* *}$ & $.24^{* *}$ & & & \\
\hline & $\begin{array}{l}\text { 4. Proximal Goals (direct } \\
\text { estimation) }\end{array}$ & $.42^{* *}$ & $.30^{* *}$ & $.70^{* *}$ & & \\
\hline & 5. Outcome Expectations & $.30^{* *}$ & $.15^{* *}$ & $.74^{* *}$ & $.50^{* *}$ & \\
\hline & 6. Self-efficacy & $.36^{* *}$ & $.26^{* *}$ & $.61^{* *}$ & $.52^{* *}$ & $.50^{* *}$ \\
\hline \multirow{6}{*}{$\begin{array}{l}\text { Prescribing } \\
\text { additional } \\
\text { therapy for } \\
\text { managing } \\
\text { glycemic } \\
\text { control }\end{array}$} & 1. Behavior (12 month self-report) & & & & & \\
\hline & 2. Behavior (baseline simulation) & -.05 & & & & \\
\hline & 3. Proximal Goals & $.30^{* *}$ & .10 & & & \\
\hline & $\begin{array}{l}\text { 4. Proximal Goals (direct } \\
\text { estimation) }\end{array}$ & $.44^{* *}$ & .02 & $.53^{* *}$ & & \\
\hline & 5. Outcome Expectations & $.24^{* *}$ & .10 & $.77^{* *}$ & $.47^{* *}$ & \\
\hline & 6. Self-efficacy & $.27^{* *}$ & .03 & $.42^{* *}$ & $.39^{* *}$ & $.43^{* *}$ \\
\hline
\end{tabular}




\begin{tabular}{lllllllll}
\hline & \multicolumn{1}{l}{ 1. Behavior (12 month self-report) } & & & & & \\
& 2. Behavior (baseline simulation) & $.24^{* *}$ & & & & \\
Providing & 3. Proximal Goals & $.43^{* *}$ & $.24^{* *}$ & & & & \\
general & 4. Proximal Goals (direct & $.54^{* *}$ & $.25^{* *}$ & $.63^{* *}$ & & \\
education & estimation) & $.30^{* *}$ & $.16^{* *}$ & $.72^{* *}$ & $.53^{* *}$ & \\
& 5. Outcome Expectations & $.31^{* *}$ & $.21^{*}$ & $.55^{* *}$ & $.36^{* *}$ & $.42^{* *}$ \\
& 6. Self-efficacy & & & & & &
\end{tabular}


Supplemental Table 3.3

Learning Theory Bivariate Associations by Behavior

\begin{tabular}{|c|c|c|c|c|c|c|}
\hline Behavior & Variable & 1 & 2 & 3 & 4 & 5 \\
\hline \multirow{6}{*}{$\begin{array}{l}\text { Providing weight } \\
\text { advice }\end{array}$} & 1. Behavior (12 month self-report) & & & & & \\
\hline & 2. Behavior (baseline simulation) & $.14^{* *}$ & & & & \\
\hline & 3. Intention (strength) & $.28^{* * *}$ & $.17^{* *}$ & & & \\
\hline & 4. Intention (direct estimation) & $.37^{* *}$ & $.15^{* *}$ & $.43^{* *}$ & & \\
\hline & 5. Anticipated Consequences & $.15^{* *}$ & $.10^{*}$ & $.31^{* *}$ & $.24^{* *}$ & \\
\hline & 6. Habit & $.33^{* *}$ & $.17^{* *}$ & $.79^{* *}$ & $.47^{* *}$ & $.27^{* *}$ \\
\hline \multirow{6}{*}{$\begin{array}{l}\text { Prescribing } \\
\text { additional } \\
\text { antihypertensive } \\
\text { drugs }\end{array}$} & 1. Behavior (12 month self-report) & & & & & \\
\hline & 2. Behavior (baseline simulation) & $.14^{* *}$ & & & & \\
\hline & 3. Intention (strength) & $.33^{* *}$ & $.22^{* *}$ & & & \\
\hline & 4. Intention (direct estimation) & $.39^{* *}$ & $.12^{*}$ & $.64^{* *}$ & & \\
\hline & 5. Anticipated Consequences & $.16^{* *}$ & .06 & $.42^{* *}$ & $.40^{* *}$ & \\
\hline & 6. Habit & $.26^{* * *}$ & $.14^{* *}$ & $.81^{* *}$ & $.51^{* *}$ & $.29^{* *}$ \\
\hline \multirow{6}{*}{$\begin{array}{l}\text { Examining feet } \\
\text { (circulation) }\end{array}$} & 1. Behavior (12 month self-report) & & & & & \\
\hline & 2. Behavior (baseline simulation) & $.32^{* *}$ & & & & \\
\hline & 3. Intention (strength) & $.69^{* *}$ & $.37^{* * *}$ & & & \\
\hline & 4. Intention (direct estimation) & $.67^{* *}$ & $.33^{* *}$ & $.85^{* *}$ & & \\
\hline & 5. Anticipated Consequences & $.15^{*}$ & .04 & $.18^{* *}$ & $.14^{*}$ & \\
\hline & 6. Habit & $.66^{* *}$ & $.37^{* *}$ & $.92^{* *}$ & $.79^{* *}$ & $.20^{* *}$ \\
\hline \multirow{6}{*}{$\begin{array}{l}\text { Providing self- } \\
\text { management } \\
\text { advice }\end{array}$} & 1. Behavior (12 month self-report) & & & & & \\
\hline & 2. Behavior (baseline simulation) & $.22^{* * *}$ & & & & \\
\hline & 3. Intention (strength) & $.41^{* *}$ & $.24^{* *}$ & & & \\
\hline & 4. Intention (direct estimation) & $.42^{* *}$ & $.30^{* *}$ & $.70^{* *}$ & & \\
\hline & 5. Anticipated Consequences & $.22^{* *}$ & .04 & $.25^{* *}$ & $.16^{* *}$ & \\
\hline & 6. Habit & $.43^{* *}$ & $.21^{* *}$ & $.92^{* *}$ & $.66^{* *}$ & $.24^{* *}$ \\
\hline \multirow{6}{*}{$\begin{array}{l}\text { Prescribing } \\
\text { additional therapy } \\
\text { for managing } \\
\text { glycemic control }\end{array}$} & 1. Behavior (12 month self-report) & & & & & \\
\hline & 2. Behavior (baseline simulation) & -.05 & & & & \\
\hline & 3. Intention (strength) & $.30^{* *}$ & .10 & & & \\
\hline & 4. Intention (direct estimation) & $.44^{* *}$ & .02 & $.53^{* *}$ & & \\
\hline & 5. Anticipated Consequences & $.16^{* *}$ & -.06 & $.24^{* *}$ & $.15^{* *}$ & \\
\hline & 6. Habit & $.33^{* *}$ & .09 & $.84^{* *}$ & $.47^{* *}$ & $.25^{* *}$ \\
\hline \multirow{3}{*}{$\begin{array}{l}\text { Providing general } \\
\text { education }\end{array}$} & 1. Behavior (12 month self-report) & & & & & \\
\hline & 2. Behavior (baseline simulation) & $.24^{* *}$ & & & & \\
\hline & 3. Intention (strength) & $.43^{* *}$ & $.24^{* *}$ & & & \\
\hline
\end{tabular}




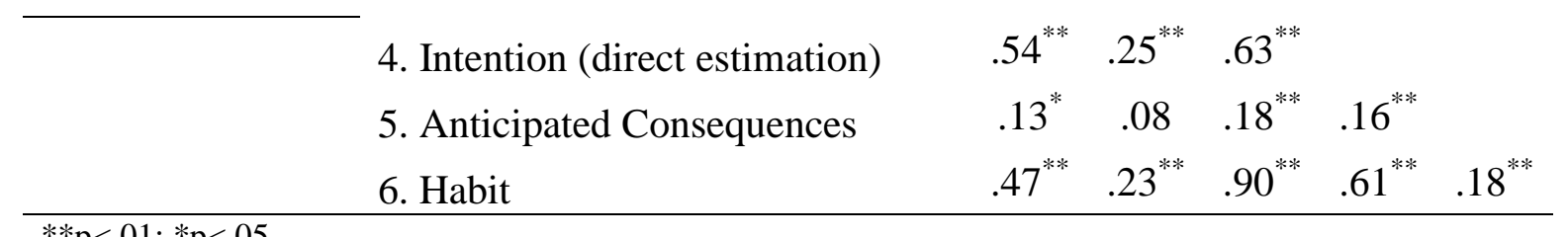

$* * \mathrm{p}<.01 ; * \mathrm{p}<.05$

Note. Habit measured with 2-item evidence of habit measure 
Supplemental Table 3.4

Planning Bivariate Associations by Behavior

\begin{tabular}{|c|c|c|c|c|}
\hline Behavior & Variable & 1 & 2 & 3 \\
\hline \multirow{4}{*}{$\begin{array}{l}\text { Providing weight } \\
\text { advice }\end{array}$} & 1. Behavior (12 month self-report) & & & \\
\hline & 2. Behavior (baseline simulation) & $.14^{* *}$ & & \\
\hline & 3. Action Planning & $.14^{* *}$ & $.16^{* *}$ & \\
\hline & 4. Coping Planning & $.28^{* *}$ & $.19^{* *}$ & $.31^{* *}$ \\
\hline \multirow{4}{*}{$\begin{array}{l}\text { Prescribing } \\
\text { additional } \\
\text { antihypertensive } \\
\text { drugs }\end{array}$} & 1. Behavior (12 month self-report) & & & \\
\hline & 2. Behavior (baseline simulation) & $.14^{* *}$ & & \\
\hline & 3. Action Planning & $.24^{* *}$ & .07 & \\
\hline & 4. Coping Planning & $.19^{* *}$ & .09 & $.48^{* *}$ \\
\hline \multirow{4}{*}{$\begin{array}{l}\text { Examining feet } \\
\text { (circulation) }\end{array}$} & 1. Behavior (12 month self-report) & & & \\
\hline & 2. Behavior (baseline simulation) & $.32^{* *}$ & & \\
\hline & 3. Action Planning & $.47^{* *}$ & $.20^{* *}$ & \\
\hline & 4. Coping Planning & $.55^{* *}$ & $.22^{* *}$ & $.64^{* *}$ \\
\hline \multirow{4}{*}{$\begin{array}{l}\text { Providing self- } \\
\text { management advice }\end{array}$} & 1. Behavior (12 month self-report) & & & \\
\hline & 2. Behavior (baseline simulation) & $.22^{* *}$ & & \\
\hline & 3. Action Planning & $.29^{* *}$ & $.17^{* *}$ & \\
\hline & 4. Coping Planning & $.37^{* *}$ & $.17^{* *}$ & $.61^{* *}$ \\
\hline \multirow{4}{*}{$\begin{array}{l}\text { Prescribing } \\
\text { additional therapy } \\
\text { for managing } \\
\text { glycemic control }\end{array}$} & 1. Behavior (12 month self-report) & & & \\
\hline & 2. Behavior (baseline simulation) & -.05 & & \\
\hline & 3. Action Planning & $.26^{* *}$ & -.01 & \\
\hline & 4. Coping Planning & $.26^{* *}$ & -.08 & $.67^{* *}$ \\
\hline \multirow{4}{*}{$\begin{array}{l}\text { Providing general } \\
\text { education }\end{array}$} & 1. Behavior (12 month self-report) & & & \\
\hline & 2. Behavior (baseline simulation) & $.24^{* *}$ & & \\
\hline & 3. Action Planning & $.43^{* *}$ & $.20^{* *}$ & \\
\hline & 4. Coping Planning & $.34^{* *}$ & $.20^{* *}$ & $.64^{* *}$ \\
\hline
\end{tabular}

$* * \mathrm{p}<.01 ; * \mathrm{p}<.05$ 
Supplemental Table 3.5

Habit Bivariate Associations by Behavior

\begin{tabular}{|c|c|c|}
\hline Behavior & Variable & Habit $^{\circ}$ \\
\hline \multirow{4}{*}{ Providing weight advice } & Behavior (12 month self-report) & $.38^{* *}$ \\
\hline & Behavior (baseline simulation) & $.13^{* *}$ \\
\hline & Intention (strength) & $.57^{* *}$ \\
\hline & Intention (direct estimation) & $.37^{* *}$ \\
\hline \multirow{4}{*}{$\begin{array}{l}\text { Prescribing additional } \\
\text { antihypertensive drugs }\end{array}$} & Behavior (12 month self-report) & $.37^{* * *}$ \\
\hline & Behavior (baseline simulation) & $.16^{* *}$ \\
\hline & Intention (strength) & $.66^{* *}$ \\
\hline & Intention (direct estimation) & $.50^{* *}$ \\
\hline \multirow{4}{*}{ Examining feet (circulation) } & Behavior (12 month self-report) & $.68^{* *}$ \\
\hline & Behavior (baseline simulation) & $.36^{* *}$ \\
\hline & Intention (strength) & $.81^{* *}$ \\
\hline & Intention (direct estimation) & $.74^{* *}$ \\
\hline \multirow{4}{*}{ Providing self-management advice } & Behavior (12 month self-report) & $.42^{* *}$ \\
\hline & Behavior (baseline simulation) & $.22^{* *}$ \\
\hline & Intention (strength) & $.76^{* *}$ \\
\hline & Intention (direct estimation) & $.63^{* *}$ \\
\hline \multirow{4}{*}{$\begin{array}{l}\text { Prescribing additional therapy for } \\
\text { managing glycemic control }\end{array}$} & Behavior (12 month self-report) & $.34^{* *}$ \\
\hline & Behavior (baseline simulation) & .02 \\
\hline & Intention (strength) & $.55^{* *}$ \\
\hline & Intention (direct estimation) & $.44^{* *}$ \\
\hline \multirow{4}{*}{ Providing general education } & Behavior (12 month self-report) & $.37^{* *}$ \\
\hline & Behavior (baseline simulation) & $.19^{* *}$ \\
\hline & Intention (strength) & $.73^{* *}$ \\
\hline & Intention (direct estimation) & $.53^{* *}$ \\
\hline
\end{tabular}

${ }^{* *} \mathrm{p}<.01 ;{ }^{*} \mathrm{p}<.05 ;{ }^{a}$ Self-reported habit index (Verplanken \& Orbell, 2003) 
Supplemental File 4 - Multilevel models predicting intention and behavior, accounting for clustering within practices

Supplemental Table 4.1

Random Intercept models of TPB Predicting Intention Strength, Direct Estimation of Intention, Simulated Behavior, and 12 Month Self-Reported Behavior

\begin{tabular}{cc}
\multicolumn{2}{c}{ Weight Advice } \\
\cline { 2 - 3 } Null & $\begin{array}{l}\text { Fixed } \\
\text { model }\end{array}$ \\
\hline
\end{tabular}

\begin{tabular}{ll}
\hline \multicolumn{2}{c}{ Prescribing (BP) } \\
\hline Null & $\begin{array}{l}\text { Fixed } \\
\text { model }\end{array}$ \\
\hline
\end{tabular}

\begin{tabular}{ll}
\hline \multicolumn{2}{c}{ Examining Feet } \\
\hline Null & $\begin{array}{l}\text { Fixed } \\
\text { model }\end{array}$ \\
\hline
\end{tabular}

\begin{tabular}{cc}
\hline \multicolumn{2}{c}{$\begin{array}{c}\text { Self-management } \\
\text { advice }\end{array}$} \\
\hline Null $\quad \begin{array}{l}\text { Fixed } \\
\text { model }\end{array}$ \\
\hline
\end{tabular}

\begin{tabular}{ll}
\hline Prescribing $(\mathrm{HbA} 1 \mathrm{c})$ \\
\hline Null & $\begin{array}{l}\text { Fixed } \\
\text { model }\end{array}$ \\
\hline
\end{tabular}

\begin{tabular}{|c|c|}
\hline \multicolumn{2}{|c|}{$\begin{array}{l}\text { Providing patient } \\
\text { education }\end{array}$} \\
\hline Null & $\begin{array}{l}\text { Fixed } \\
\text { model }\end{array}$ \\
\hline
\end{tabular}

Fixed effects

Attitude [B (SE)]

Subjective Norm [B (SE)

$\mathrm{PBC}$ [B (SE)]

Variance components

Level $2\left(\sigma^{2}{ }_{\mu 0} ; \mathrm{SE}\right)$

Level $1\left(\sigma_{e 0}^{2} ; \mathrm{SE}\right)$

$\begin{array}{ll}-- & .38(.04)^{* *} \\ -- & .29(.03)^{* *} \\ -- & .17(.03)^{* *}\end{array}$

Dependent variable: Intention (strength)

odel fit

$\begin{array}{ll}.00(.00) & .00(.00) \\ .73(.05) & .35(.02)\end{array}$

$\begin{array}{ll}-- & .57(.04)^{* *} \\ -- & .33(.04)^{* *} \\ -- & .14(.03)^{* *}\end{array}$

$\begin{array}{ll}-- & .31(.07)^{* *} \\ -- & .73(.05)^{* *} \\ -- & .18(.05)^{* *}\end{array}$

$--\quad .38(.05)^{* *}$

$-.03(.04) *$
$--\quad .03)^{* *}$

$.00(.00) \quad .00(.00)$

$0.09(.13) \quad .03(.04)$

$.00(.00) \quad .00(.01)$

$2.70(.25)$

$.72(.07)$

$1.36(.10)$

$.38(.03)$

$.04(.04)$

$.48(.05) * *$

$--\quad .36(.05)^{* *}$

Devia

$\Delta$ null model

$1233.48 \quad 874.61$

$1171.05 \quad 633.48$

792.63

763.41

Dependent variable: Intention (direct estimation)

Fixed effects

Attitude [B (SE)]

Subjective Norm [B (SE)]

PBC [B (SE)]

Variance components

Level $2\left(\sigma^{2}{ }^{2} ; \mathrm{SE}\right)$

Level $1\left(\sigma_{e 0}^{2} ; \mathrm{SE}\right)$

Model fit

Deviance (-2 log likelihood)

$\begin{array}{ll}-- & .59(.13)^{* *} \\ -- & .20(.10)^{*} \\ -- & .11(.08)\end{array}$

Dependent $v$

$\Delta$ null model

$.36(.15) \quad .16(.1$

$2.95(.22) \quad 2.70(.20)$

$\begin{array}{lc}-- & 1.09(.12)^{* *} \\ -- & .16(.11)\end{array}$

-- $\quad .43(.20)^{*}$

$.43(.20)^{*}$
$1.34(.13)^{* *}$

$--\quad .56(.17)^{* *}$

$--\quad .12(.09)$

$--\quad .18(.14)$

$--\quad .50(.13)^{* *}$

$.62(.10)^{* *}$

$.73(.17)^{* * *}$

$--\quad .34(.13)^{*}$

$-\quad .23(.10)^{*}$

$--\quad .35(.03)^{* *}$

$--\quad .37(.03) * *$

$.15(.03)^{* *}$

$.00(.00) \quad$.01 (.01)

$1.05(.07) \quad .30(.02)$

$898.80 \quad 545.95$

$352.85^{* *}$

1194.54

689.56

$504.98 * *$

Fixed effects

Intention [B (SE)]

$\mathrm{PBC}$ [B (SE)]

Variance components

1792.87

1733.38

$\begin{array}{cc}.13(.18) & .12(.11) \\ 4.30(.36) & 2.53(.21)\end{array}$

$.19(.59) \quad .00(.28)$

$.00(.00) \quad .00(.00)$

$.61(.25)$

.17 (.14)

$\begin{array}{ll}11.65 & 5.81(.57)\end{array}$

$5.50(.40) \quad 3.45(.25)$

$3.30(.30) \quad 2.67(.24)$

$12(.16)$

$3.98(.31)$

1698.56

1516.52

$59.49^{* *}$

1386.86
$186.98^{* *}$

$1470.54 \quad 1269.04$

$1703.34 \quad 1528.41$

$174.93 * *$

1353.6

1248.26

$105.34 * *$

$182.04 * *$

Dependent variable: Simulated Behavior

$.39(.15)^{* *}$

$.15(.11)$

$--\quad .42(.11)^{* *}$

$.09(.12)$

\begin{abstract}
$.58(.10)^{* *}$
\end{abstract}
$.09(.14)$

$.42(.15)^{* *}$

$.17(.15)$

$\begin{array}{ll}-- & .17(.08)^{*} \\ -- & -.05(.07)\end{array}$

$-.05(.07)$

$\begin{array}{cc}-- & .47(.16)^{* *} \\ -- & .15(.15)\end{array}$


PREDICTORS OF CLINICIAN BEHAVIORS IN MANAGING DIABETES

\begin{tabular}{|c|c|c|c|c|c|c|c|c|c|c|c|c|}
\hline Level $2\left(\sigma^{2}{ }_{u 0} ; \mathrm{SE}\right)$ & $.48(.24)$ & $.34(.22)$ & $.33(.18)$ & $.24(.20)$ & $.11(.21)$ & $.00(.00)$ & $.00(.00)$ & $.00(.00)$ & $.06(.05)$ & $.06(.07)$ & $.00(.00)$ & $.28(.25)$ \\
\hline Level $1\left(\sigma_{e 0}^{2} ; \mathrm{SE}\right)$ & $5.85(.41)$ & $5.72(.41)$ & $4.58(.32)$ & $4.52(.36)$ & $6.11(.47)$ & $5.62(.47)$ & $5.91(.41)$ & $5.73(.43)$ & $1.50(.10)$ & $1.53(.13)$ & $6.15(.40)$ & $5.63(.45)$ \\
\hline \multicolumn{13}{|l|}{ Model fit } \\
\hline $\begin{array}{l}\text { Deviance }(-2 \log \\
\text { likelihood) }\end{array}$ & 2320.88 & 2182.10 & 2187.34 & 1700.07 & 1949.39 & 1328.03 & 1951.83 & 1650.30 & 1632.21 & 1098.65 & 2163.92 & 1806.92 \\
\hline$\Delta$ null model & & $138.78 * *$ & & $487.27 * *$ & & $621.36^{* *}$ & & $301.53 * *$ & & $533.56 * *$ & & $357.00 * *$ \\
\hline \multicolumn{13}{|c|}{ Dependent variable: 12 month self-report } \\
\hline \multicolumn{13}{|l|}{ Fixed effects } \\
\hline Intention [B (SE)] & -- & $.52(.14)^{* *}$ & -- & $.73(.13)^{* *}$ & -- & $1.53(.13)^{* *}$ & -- & $.66(.13)^{* *}$ & -- & $.61(.16)^{* *}$ & -- & $.76(.15)^{* *}$ \\
\hline $\mathrm{PBC}[\mathrm{B}(\mathrm{SE})]$ & -- & $.30(.11)^{* *}$ & -- & $.09(.13)$ & -- & $.24(.16)$ & -- & $.23(.13)$ & -- & $.23(.15)$ & -- & $.35(.13)^{* *}$ \\
\hline \multicolumn{13}{|l|}{ Variance components } \\
\hline Level $2\left(\sigma_{u 0}^{2} ; \mathrm{SE}\right)$ & $.19(.18)$ & $.05(.14)$ & $.46(.28)$ & $.24(.23)$ & $.77(.68)$ & $.11(.29)$ & $.18(.23)$ & $.61(.25)$ & $.27(.31)$ & $.30(.27)$ & $.17(.22)$ & $.03(.16)$ \\
\hline Level $1\left(\sigma_{e 0}^{2} ; \mathrm{SE}\right)$ & $5.62(.38)$ & $4.38(.33)$ & $6.23(.48)$ & $5.02(.43)$ & $\begin{array}{l}11.29 \\
(1.11)\end{array}$ & $4.62(.51)$ & $6.33(.48)$ & $3.65(.32)$ & $6.77(.58)$ & $4.79(.46)$ & $6.55(.47)$ & $3.94(.33)$ \\
\hline \multicolumn{13}{|l|}{ Model fit } \\
\hline $\begin{array}{l}\text { Deviance }(-2 \log \\
\text { likelihood) }\end{array}$ & 2362.02 & 1842.33 & 1986.11 & 1559.27 & 1495.34 & 979.34 & 2001.34 & 1438.71 & 1665.70 & 1302.24 & 2232.83 & 1487.87 \\
\hline$\Delta$ null model & & $519.69 * *$ & & $426.84 * *$ & & $516.00 * *$ & & $562.63 * *$ & & $363.46^{* *}$ & & $744.96 * *$ \\
\hline
\end{tabular}

Note. $\mathrm{BP}=$ prescribing additional antihypertensive drugs; Feet=examining foot circulation and sensation; $\mathrm{PBC}=$ perceived behavioral control.

TPB MLM (combined Level 1 and Level 2) equations:

Intention Strength $i j=\mathrm{B}_{0}+\mathrm{B}_{1}(\text { Attitude })_{i j}+\mathrm{B}_{2}(\text { Subjective Norm })_{i j}+\mathrm{B}_{3}(\text { Perceived Behavioral Control })_{i j}+u_{0 j}+e_{0 i j}$

Direct Estimation of Intention $i j=\mathrm{B}_{0}+\mathrm{B}_{1}(\text { Attitude })_{i j}+\mathrm{B}_{2}$ (Subjective Norm $)_{i j}+\mathrm{B}_{3}(\text { Perceived Behavioral Control })_{i j}+u_{0 j}+e_{0 i j}$

Simulated Behavior $i j=\mathrm{B}_{0}+\mathrm{B}_{1}$ (Intention Strength) $)_{i j}+\mathrm{B}_{2}$ (Perceived Behavioral Control $)_{i j}+u_{0 \mathrm{j}}+e_{0 \mathrm{j}}$

12 month self-reported behavior $i j=\mathrm{B}_{0}+\mathrm{B}_{1}$ (Intention Strength $)_{i j}+\mathrm{B}_{2}(\text { Perceived Behavioral Control })_{i j}+u_{0 j}+e_{0 i j}$ 
Supplemental Table 4.2

Random Intercept Models of SCT Predicting Intention Strength, Direct Estimation of Intention, Simulated Behavior, and 12 Month Self-Reported Behavior

\begin{tabular}{|c|c|c|c|c|c|c|c|c|c|c|c|c|}
\hline & \multicolumn{2}{|c|}{ Weight Advice } & \multicolumn{2}{|c|}{ Prescribing (BP) } & \multicolumn{2}{|c|}{ Examining Feet } & \multicolumn{2}{|c|}{$\begin{array}{c}\text { Self-management } \\
\text { advice }\end{array}$} & \multicolumn{2}{|c|}{$\begin{array}{c}\text { Prescribing } \\
(\mathrm{HbA} 1 \mathrm{c})\end{array}$} & \multicolumn{2}{|c|}{$\begin{array}{c}\text { Providing patient } \\
\text { education }\end{array}$} \\
\hline & Null & $\begin{array}{l}\text { Fixed } \\
\text { model }\end{array}$ & Null & $\begin{array}{l}\text { Fixed } \\
\text { model }\end{array}$ & Null & $\begin{array}{l}\text { Fixed } \\
\text { model }\end{array}$ & Null & $\begin{array}{l}\text { Fixed } \\
\text { model }\end{array}$ & Null & $\begin{array}{l}\text { Fixed } \\
\text { model }\end{array}$ & Null & $\begin{array}{l}\text { Fixed } \\
\text { model }\end{array}$ \\
\hline \multicolumn{13}{|l|}{ Fixed effects } \\
\hline Outcome expectancies [B (SE)] & -- & $.60(.04)^{* *}$ & -- & $.85(.03)^{* *}$ & -- & $1.06(.07)^{* *}$ & -- & $.81(.05)^{* *}$ & -- & $.87(.05)^{* *}$ & -- & $.80(.05)^{* *}$ \\
\hline Self-efficacy [B (SE)] & -- & $.21(.03)^{* * *}$ & -- & $.14(.03)^{* *}$ & -- & $.23(.05)^{* *}$ & -- & $.36(.04)^{* *}$ & -- & $.10(.03)^{* * *}$ & -- & $.30(.03)^{* *}$ \\
\hline \multicolumn{13}{|l|}{ Variance components } \\
\hline Level $2\left(\sigma_{u 0}^{2} ; \mathrm{SE}\right)$ & $.00(.00)$ & $.00(.00)$ & $.00(.00)$ & $.00(.00)$ & $0.09(.13)$ & $.07(.06)$ & $.00(.00)$ & $.01(.02)$ & $.04(.04)$ & $.00(.00)$ & $.00(.00)$ & $.02(.02)$ \\
\hline Level $1\left(\sigma_{e 0}^{2} ; \mathrm{SE}\right)$ & $.73(.05)$ & $.37(.02)$ & $1.19(.09)$ & $.32(.02)$ & $2.70(.25)$ & $1.10(.10)$ & $\begin{array}{l}1.36 \\
(.10)\end{array}$ & $.51(.04)$ & $.84(.07)$ & $.34(.03)$ & $\begin{array}{l}1.05 \\
(.07)\end{array}$ & $.40(.03)$ \\
\hline \multicolumn{13}{|l|}{ Model fit } \\
\hline Deviance (-2 log likelihood) & 1233.48 & 900.29 & 1171.05 & 651.78 & 1204.80 & 927.86 & 1280.13 & 889.34 & 898.80 & 592.77 & 1194.54 & 817.25 \\
\hline \multicolumn{13}{|c|}{ Dependent variable: Intention (direct estimation) } \\
\hline Fixed effects & & & & & & & & & & & & \\
\hline Outcome expectancies [B (SE)] & -- & $.54(.12)^{* *}$ & -- & $1.12(.09)^{* *}$ & -- & $1.68(.18)^{* *}$ & -- & $.90(.14)^{* *}$ & -- & $.90(.14)^{* *}$ & -- & $1.27(.13)^{* *}$ \\
\hline Self-efficacy [B (SE)] & -- & $.38(.08)^{* *}$ & -- & $.37(.08)^{* *}$ & -- & $.44(.14)^{* *}$ & -- & $.79(.11)^{* *}$ & -- & $.39(.09)^{* *}$ & -- & $.31(.09)^{* *}$ \\
\hline \multicolumn{13}{|l|}{ Variance components } \\
\hline Level $2\left(\sigma_{\mu 0}^{2} ; \mathrm{SE}\right)$ & $.36(.15)$ & $.15(.11)$ & $.13(.18)$ & $.11(.11)$ & $.16(.58)$ & $.10(.37)$ & $.00(.00)$ & $.00(.13)$ & $.61(.25)$ & $.14(.13)$ & $.12(.16)$ & $.09(.11)$ \\
\hline Level $1\left(\sigma_{e 0}^{2} ; \mathrm{SE}\right)$ & $2.95(.22)$ & $2.61(.19)$ & $4.30(.36)$ & $2.46(.21)$ & $\begin{array}{l}11.67 \\
(1.14)\end{array}$ & $7.26(.71)$ & $\begin{array}{l}5.50 \\
(.40)\end{array}$ & $3.60(.29)$ & $\begin{array}{l}3.30 \\
(.30)\end{array}$ & $2.67(.24)$ & $\begin{array}{l}3.98 \\
(.31)\end{array}$ & $2.75(.22)$ \\
\hline \multicolumn{13}{|l|}{ Model fit } \\
\hline Deviance (-2 log likelihood) & 1792.87 & 1711.83 & 1573.84 & 1364.15 & 1475.48 & 1333.88 & 1703.34 & 1544.70 & 1353.60 & 1252.71 & 1698.56 & 1529.44 \\
\hline
\end{tabular}


PREDICTORS OF CLINICIAN BEHAVIORS IN MANAGING DIABETES

\begin{tabular}{|c|c|c|c|c|c|c|c|c|c|c|c|c|}
\hline$\Delta$ null model & & $81.04 * *$ & & $209.69 * *$ & & $141.60 * *$ & & $158.64 * *$ & & $100.89 * *$ & & $169.12 * *$ \\
\hline \multicolumn{13}{|c|}{ Dependent variable: Simulated Behavior } \\
\hline \multicolumn{13}{|l|}{ Fixed effects } \\
\hline Outcome expectancies [B (SE)] & -- & $.46(.19)^{* *}$ & -- & $-.01(.20)$ & -- & $-.16(.21)$ & -- & $-.22(.22)$ & -- & $.08(.14)$ & -- & $-.11(.23)$ \\
\hline Self-efficacy [B (SE)] & -- & $.48(.12)^{* *}$ & -- & $.17(.11)$ & -- & $.37(.13)^{* *}$ & -- & $.42(.15)^{* *}$ & -- & $-.02(.07)$ & -- & $.22(.13)$ \\
\hline Proximal goals [B (SE)] & -- & $-.12(.18)$ & -- & $.34(.19)$ & -- & $.51(.13)^{* *}$ & -- & $.42(.17)^{*}$ & -- & $.10(.12)$ & -- & $.52(.19)^{* *}$ \\
\hline \multicolumn{13}{|l|}{ Variance components } \\
\hline Level $2\left(\sigma_{u 0}^{2} ; \mathrm{SE}\right)$ & $.48(.24)$ & $.33(.21)$ & $.33(.18)$ & $.22(.19)$ & $.12(.22)$ & $.00(.00)$ & $.00(.00)$ & $.03(.21)$ & $.06(.05)$ & $.06(.07)$ & $.00(.00)$ & $.29(.25)$ \\
\hline Level $1\left(\sigma_{e 0}^{2} ; \mathrm{SE}\right)$ & $5.85(.41)$ & $5.38(.39)$ & $4.58(.32)$ & $4.47(.36)$ & 6.14(.47) & $5.58(.46)$ & $\begin{array}{l}5.91 \\
(.41)\end{array}$ & $5.60(.47)$ & $\begin{array}{l}1.50 \\
(.10)\end{array}$ & $1.53(.13)$ & $\begin{array}{l}6.15 \\
(.40)\end{array}$ & $5.51(.44)$ \\
\hline \multicolumn{13}{|l|}{ Model fit } \\
\hline Deviance (-2 log likelihood) & 2320.88 & 2144.55 & 2187.34 & 1677.14 & 1956.95 & 1325.83 & 1951.83 & 1643.37 & 1632.21 & 1098.77 & 2163.92 & 1795.80 \\
\hline$\Delta$ null model & & $176.33 * *$ & & $510.20 * *$ & & $631.12 * *$ & & $308.46 * *$ & & $533.44 * *$ & & $368.12 * *$ \\
\hline \multicolumn{13}{|c|}{ Dependent variable: 12 month self-report } \\
\hline Fixed effects & & & & & & & & & & & & \\
\hline Outcome expectancies [B (SE)] & -- & $.03(.18)$ & -- & $.06(.24)$ & -- & $-.50(.24)^{*}$ & -- & $-.09(.20)$ & -- & $-.06(.27)$ & -- & $-.09(.21)$ \\
\hline Self-efficacy [B (SE)] & -- & $.34(.11)^{* *}$ & -- & $.36(.13)^{* *}$ & -- & $.53(.15)^{* *}$ & -- & $.40(.14)^{* *}$ & -- & $.36(.14)^{*}$ & -- & $.24(.12)^{*}$ \\
\hline Proximal goals [B (SE)] & -- & $.47(.17)^{* *}$ & -- & $.54(.23)^{*}$ & -- & $1.59(.16)^{* *}$ & -- & $.63(.16)^{* *}$ & -- & $.59(.22)^{* *}$ & -- & $.94(.18)^{* *}$ \\
\hline \multicolumn{13}{|l|}{ Variance components } \\
\hline Level $2\left(\sigma^{2}{ }_{u 0} ; \mathrm{SE}\right)$ & $.19(.18)$ & $.01(.14)$ & $.46(.28)$ & $.26(.23)$ & $.71(.67)$ & $.10(.27)$ & $.18(.23)$ & $.61(.25)$ & $.27(.31)$ & $.17(.25)$ & $.17(.22)$ & $.00(.00)$ \\
\hline Level $1\left(\sigma_{e 0}^{2} ; \mathrm{SE}\right)$ & $5.62(.38)$ & $4.41(.33)$ & $6.23(.48)$ & $4.92(.42)$ & $\begin{array}{l}11.34 \\
(1.11)\end{array}$ & $4.39(.49)$ & $\begin{array}{l}6.33 \\
(.48)\end{array}$ & $3.58(.32)$ & $\begin{array}{l}6.77 \\
(.58)\end{array}$ & $4.84(.46)$ & $\begin{array}{l}6.55 \\
(.47)\end{array}$ & $3.96(.30)$ \\
\hline \multicolumn{13}{|l|}{ Model fit } \\
\hline Deviance (-2 log likelihood) & 2362.02 & 1833.13 & 1986.11 & 1544.86 & 1500.71 & 971.89 & 2001.34 & 1433.11 & 1665.70 & 1298.63 & 2232.83 & 1483.07 \\
\hline$\Delta$ null model & & $528.89 * *$ & 441.25 & $441.25 * *$ & & $528.82 * *$ & & $568.23 * *$ & & $367.07 * *$ & & $749.76 * *$ \\
\hline
\end{tabular}

Note. $\mathrm{BP}=$ prescribing additional antihypertensive drugs; Feet=examining foot circulation and sensation SCT MLM (combined Level 1 and Level 2) equations: 
Intention Strength $i j=\mathrm{B}_{0}+\mathrm{B}_{1}(\text { Outcome Expectancies })_{i j}+\mathrm{B}_{2}$ (Self-efficacy $)_{i j}+u_{0 j}+e_{0 i j}$

Direct estimation of intention $i j=\mathrm{B}_{0}+\mathrm{B}_{1}(\text { Outcome Expectancies })_{i j}+\mathrm{B}_{2}(\text { Self-efficacy })_{i j}+u_{0 j}+e_{0 i j}$

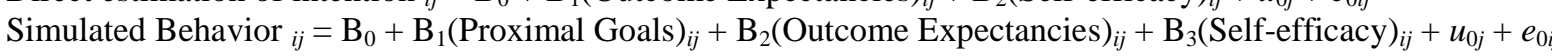

12 month self-reported behavior $i j=\mathrm{B}_{0}+\mathrm{B}_{1}(\text { Proximal Goals })_{i j}+\mathrm{B}_{2}$ (Outcome Expectancies $)_{i j}+\mathrm{B}_{3}(\text { Self-efficacy })_{i j}+u_{0 j}+e_{0 i j}$ 
Supplemental Table 4.3

Random Intercept Models of LT Predicting Simulated Behavior and 12 Month Self-Reported Behavior

\begin{tabular}{|c|c|c|c|c|c|c|c|c|c|c|c|c|}
\hline & \multicolumn{2}{|c|}{ Weight Advice } & \multicolumn{2}{|c|}{ Prescribing (BP) } & \multicolumn{2}{|c|}{ Examining Feet } & \multicolumn{2}{|c|}{$\begin{array}{c}\text { Self-management } \\
\text { advice }\end{array}$} & \multicolumn{2}{|c|}{$\begin{array}{c}\text { Prescribing } \\
(\mathrm{HbA} 1 \mathrm{c})\end{array}$} & \multicolumn{2}{|c|}{$\begin{array}{c}\text { Providing patient } \\
\text { education }\end{array}$} \\
\hline & Null & $\begin{array}{l}\text { Fixed } \\
\text { model }\end{array}$ & Null & $\begin{array}{l}\text { Fixed } \\
\text { model }\end{array}$ & Null & $\begin{array}{l}\text { Fixed } \\
\text { model }\end{array}$ & Null & $\begin{array}{l}\text { Fixed } \\
\text { model } \\
\end{array}$ & Null & $\begin{array}{c}\text { Fixed } \\
\text { model }\end{array}$ & Null & $\begin{array}{l}\text { Fixed } \\
\text { model }\end{array}$ \\
\hline \multicolumn{13}{|c|}{ Dependent variable: Simulated Behavior } \\
\hline \multicolumn{13}{|l|}{ Fixed effects } \\
\hline Anticipated Consequences [B (SE)] & -- & $.16(.12)$ & -- & $.03(.10)$ & -- & $-.14(.17)$ & -- & $-.02(.13)$ & -- & $-.08(.07)$ & -- & $.06(.11)$ \\
\hline Evidence of Habit [B (SE)] & -- & $.40(.12)^{* *}$ & -- & $.26(.10)^{* *}$ & -- & $.63(.09)^{* *}$ & -- & $.47(.11)^{* *}$ & -- & $.12(.07)$ & -- & $.51(.11)^{* *}$ \\
\hline Level $2\left(\sigma_{u 0}^{2} ; \mathrm{SE}\right)$ & $.48(.24)$ & $.44(.24)$ & $.33(.18)$ & $.29(.210)$ & $.11(.21)$ & $.00(.00)$ & $.00(.00)$ & $.11(.23)$ & $.06(.05)$ & $.06(.07)$ & $.00(.00)$ & $.34(.26)$ \\
\hline Level $1\left(\sigma_{e 0}^{2} ; \mathrm{SE}\right)$ & $5.85(.41)$ & $5.68(.41)$ & $\begin{array}{l}4.58 \\
(.32)\end{array}$ & $4.60(.37)$ & $6.11(.47)$ & $5.68(.47)$ & $\begin{array}{l}5.91 \\
(.41)\end{array}$ & $5.76(.48)$ & $\begin{array}{l}1.50 \\
(.10)\end{array}$ & $1.50(.13)$ & $\begin{array}{l}6.15 \\
(.40)\end{array}$ & $5.62(.45)$ \\
\hline \multicolumn{13}{|l|}{ Model fit } \\
\hline Deviance (-2 log likelihood) & 2320.88 & 2189.12 & 2187.34 & 1692.44 & 1949.39 & 1326.59 & 1951.83 & 1658.11 & 1632.21 & 1081.31 & 2163.92 & 1804.89 \\
\hline$\Delta$ null model & & $131.76^{* * *}$ & & $494.90 * *$ & & $622.80 * *$ & & $293.72 * *$ & & $550.90 * *$ & & $359.03 * *$ \\
\hline \multicolumn{13}{|c|}{ Dependent variable: 12 month self-report } \\
\hline \multicolumn{13}{|l|}{ Fixed effects } \\
\hline Evidence of Habit [B (SE)] & -- & $.69(.11)^{* *}$ & -- & $.50(.12)^{* *}$ & -- & $\begin{array}{l}1.48 \\
(.12)^{* *}\end{array}$ & -- & $.79(.10)^{* *}$ & -- & $.72(.14)^{* *}$ & -- & $.98(.10)^{* *}$ \\
\hline \multicolumn{13}{|l|}{ Variance components } \\
\hline Level $2\left(\sigma^{2}{ }^{2} ; \mathrm{SE}\right)$ & $.19(.18)$ & $.06(.14)$ & $.46(.28)$ & $.17(.23)$ & $.77(.68)$ & $.22(.34)$ & $.18(.23)$ & $.56(.24)$ & $.27(.31)$ & $.25(.26)$ & $.17(.22)$ & $.13(.17)$ \\
\hline Level $1\left(\sigma_{e 0}^{2} ; \mathrm{SE}\right)$ & $5.62(.38)$ & $4.27(.32)$ & $\begin{array}{l}6.23 \\
(.48)\end{array}$ & $5.29(.45)$ & $\begin{array}{l}11.29 \\
(1.11)\end{array}$ & $5.01(.56)$ & $\begin{array}{l}6.33 \\
(.48)\end{array}$ & $3.57(.31)$ & $\begin{array}{l}6.77 \\
(.58)\end{array}$ & $4.76(.45)$ & $\begin{array}{l}6.55 \\
(.47)\end{array}$ & $3.72(.32)$ \\
\hline \multicolumn{13}{|l|}{ Model fit } \\
\hline Deviance (-2 log likelihood) & 2362.02 & 1836.77 & 1986.11 & 1555.21 & 1495.34 & 1005.73 & 2001.34 & 1433.48 & 1665.70 & 1284.38 & 2232.83 & 1472.56 \\
\hline$\Delta$ null model & & $525.25 * *$ & & $430.90 * *$ & & $489.61 * *$ & & $567.86^{* *}$ & & $381.32 * *$ & & $760.27 * *$ \\
\hline
\end{tabular}

Note. $\mathrm{BP}=$ prescribing additional antihypertensive drugs; Feet=examining foot circulation and sensation

Learning Theory MLM (combined Level 1 and Level 2) equations:

Simulated Behavior ${ }_{\mathrm{ij}}=\mathrm{B}_{0}+\mathrm{B}_{1}$ (Anticipated Consequences $)_{i j}+\mathrm{B}_{2}$ (Evidence of Habit $)_{i j}+u_{0 j}+e_{0 i j}$

12 month self-reported behavior $i j=\mathrm{B}_{0}+\mathrm{B}_{1}$ (Anticipated Consequences) $)_{i j}+\mathrm{B}_{2}$ (Evidence of Habit $)_{i j}+u_{0 j}+e_{0 i j}$ 
Supplemental Table 4.4

Random Intercept Models of Habit (SRHI) Predicting Simulated Behavior and 12 Month Self-Reported Behavior

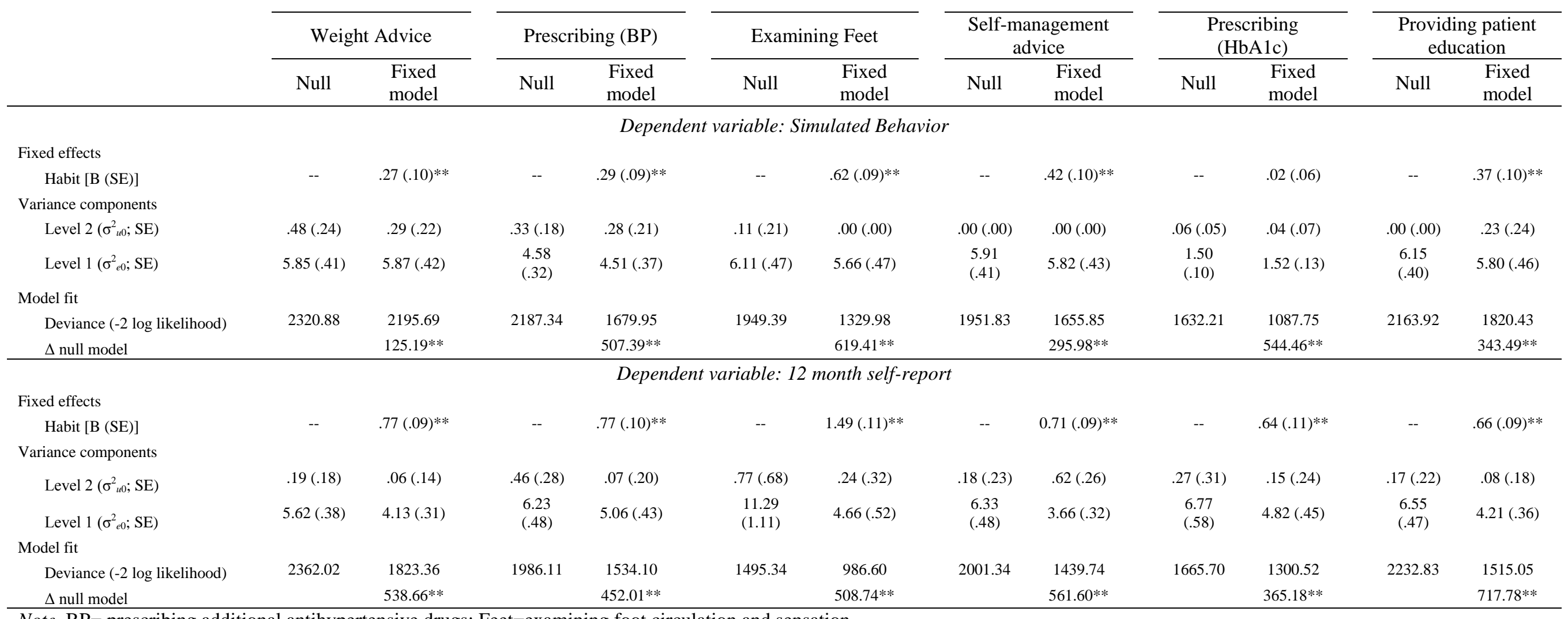

Note $. \mathrm{BP}=$ prescribing additional antihypertensive drugs; Feet=examining foot circulation and sensation

Habit MLM (combined Level 1 and Level 2) equations:

Simulated Behavior $i j=\mathrm{B}_{0}+\mathrm{B}_{1}(\text { Habit })_{i j}+u_{0 j}+e_{0 i j}$

12 month self-reported behavior $i j=\mathrm{B}_{0}+\mathrm{B}_{1}(\text { Habit })_{i j}+u_{0 j}+e_{0 i j}$ 
Supplemental Table 4.5

Random Intercept Models of Planning Predicting Simulated Behavior and 12 Month Self-Reported Behavior

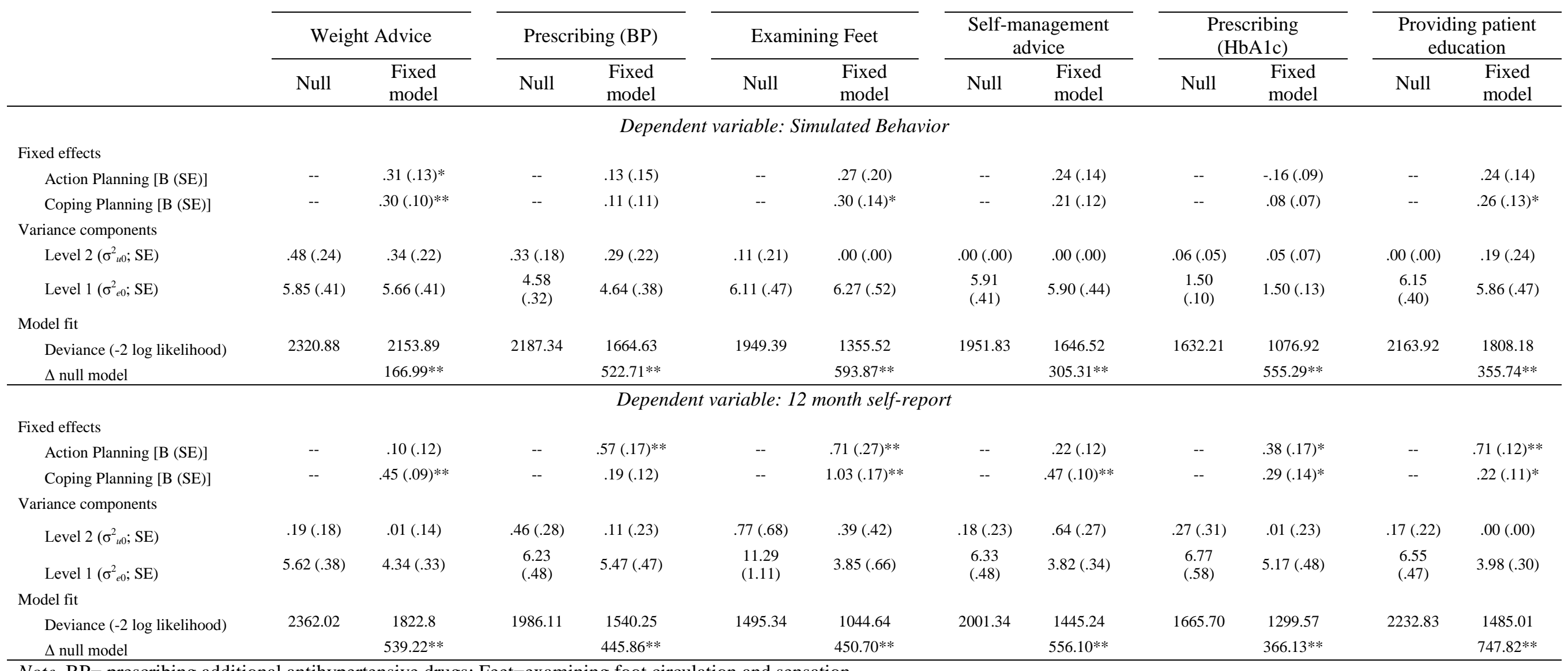

Note $. \mathrm{BP}=$ prescribing additional antihypertensive drugs; Feet=examining foot circulation and sensation

Planning MLM (combined Level 1 and Level 2) equations:

Simulated Behavior $i j=\mathrm{B}_{0}+\mathrm{B}_{1}$ (Action Planning $)_{i j}+\mathrm{B}_{2}$ (Coping Planning $)_{i j}+u_{0 j}+e_{0 i j}$

12 month self-reported behavior $i j=\mathrm{B}_{0}+\mathrm{B}_{1}$ (Action Planning $)_{i j}+\mathrm{B}_{2}(\text { Coping Planning })_{i j}+u_{0 j}+e_{0 i j}$ 
Supplemental File 5 - Detailed results of standard multiple regression analyses

Supplemental Table 5.1

Predicting intention and reported provision of advice about weight management

\begin{tabular}{|c|c|c|c|c|c|c|c|c|c|c|c|c|c|}
\hline \multirow{2}{*}{ Model } & \multirow{2}{*}{$\begin{array}{c}\text { Process (explanatory) } \\
\text { variables }\end{array}$} & \multicolumn{3}{|c|}{ Intention Strength } & \multicolumn{3}{|c|}{$\begin{array}{c}\text { Direct Estimation of } \\
\text { Intention }\end{array}$} & \multicolumn{3}{|c|}{ Simulated Behavior } & \multicolumn{3}{|c|}{$\begin{array}{c}\text { Self-reported Behavior } \\
(12 \mathrm{~m})\end{array}$} \\
\hline & & $B$ & $\beta$ & $R_{(a d j)}^{2}$ & $B$ & $\beta$ & $R_{(a d j)}^{2}$ & $B$ & $\beta$ & $R_{(a d j)}^{2}$ & $B$ & $\beta$ & $R_{(a d j)}^{2}$ \\
\hline \multirow{3}{*}{ TPB } & Attitude & $0.38 * *$ & 0.35 & \multirow{3}{*}{0.52} & $0.63 * *$ & 0.27 & \multirow{3}{*}{0.13} & -- & -- & -- & -- & -- & -- \\
\hline & Subjective Norm & $0.29 * *$ & 0.33 & & $0.21 *$ & 0.11 & & -- & -- & -- & -- & -- & -- \\
\hline & $\mathrm{PBC}$ & $0.17 * *$ & 0.22 & & 0.10 & 0.06 & & -- & -- & -- & -- & -- & -- \\
\hline \multirow{2}{*}{ ТPB } & $\mathrm{PBC}$ & -- & -- & -- & -- & -- & -- & 0.16 & 0.07 & \multirow{2}{*}{0.03} & $0.30 * *$ & 0.15 & \multirow{2}{*}{0.09} \\
\hline & Intention Strength & -- & -- & -- & -- & -- & -- & $0.39 *$ & 0.13 & & $0.52 * *$ & 0.20 & \\
\hline \multirow[b]{2}{*}{ ТPB } & $\mathrm{PBC}$ & -- & -- & -- & -- & -- & -- & $0.23 *$ & 0.10 & \multirow[b]{2}{*}{0.03} & $0.40 * *$ & 0.20 & \multirow[b]{2}{*}{0.17} \\
\hline & $\begin{array}{l}\text { Direct Estimation of } \\
\text { Intention }\end{array}$ & -- & -- & -- & -- & -- & -- & $0.18 * *$ & 0.13 & & $0.42 * *$ & 0.33 & \\
\hline \multirow{3}{*}{ SCT } & Outcome Expectations & $0.60 * *$ & 0.54 & \multirow{3}{*}{0.49} & $0.58 * *$ & 0.24 & 016 & $0.50 *$ & 0.15 & \multirow{3}{*}{0.07} & 0.03 & 0.01 & \multirow{3}{*}{0.09} \\
\hline & Self-Efficacy & $0.20 * *$ & 0.26 & & $0.39 * *$ & 0.24 & 0.10 & $0.45 * *$ & 0.20 & & $0.33 * *$ & 0.17 & \\
\hline & Proximal Goals & & & & & & & -0.11 & -0.04 & & $0.48 * *$ & 0.18 & \\
\hline \multirow{2}{*}{ LT v1 } & Anticipated Consequences & $0.09 * *$ & 0.10 & \multirow{2}{*}{0.63} & $0.22 * *$ & 0.12 & 023 & 0.16 & 0.06 & \multirow{2}{*}{0.03} & 0.15 & 0.07 & \\
\hline & Evidence of Habit & $0.65 * *$ & 0.76 & & $0.78 * *$ & 0.43 & $0.2 J$ & $0.39 * *$ & 0.15 & & $0.70 * *$ & 0.31 & 0.11 \\
\hline \multirow{2}{*}{ LT v2 } & Anticipated Consequences & $0.20 * *$ & 0.23 & \multirow{2}{*}{0.37} & $0.34 * *$ & 0.18 & 017 & 0.22 & 0.09 & \multirow{2}{*}{0.02} & $0.21 *$ & 0.09 & \multirow{2}{*}{0.15} \\
\hline & Self-reported Habit Index & $0.41 * *$ & 0.53 & & $0.55 * *$ & 0.34 & 0.17 & $0.24 *$ & 0.11 & & $0.73 * *$ & 0.36 & \\
\hline $\mathrm{n} / \mathrm{a}$ & Self-reported Habit Index & $0.44 * *$ & 0.57 & 0.32 & $0.60 * *$ & 0.37 & 0.14 & $0.28 * *$ & 0.13 & 0.01 & $0.77 * *$ & 0.38 & 0.14 \\
\hline \multirow{2}{*}{ Planning } & Action Planning & -- & -- & -- & -- & -- & -- & $0.30 *$ & 0.11 & \multirow{2}{*}{0.04} & 0.10 & 0.04 & \multirow{2}{*}{0.07} \\
\hline & Coping Planning & -- & -- & -- & -- & -- & -- & $0.30 * *$ & 0.15 & & $0.45 * *$ & 0.26 & \\
\hline
\end{tabular}

$* * \mathrm{p}<0.01 ; * \mathrm{p}<0.05 ; \mathrm{PBC}=$ perceived behavioral control 
Supplemental Table 5.2

Predicting intention and reported prescription of additional antihypertensive drugs

\begin{tabular}{|c|c|c|c|c|c|c|c|c|c|c|c|c|c|}
\hline \multirow{2}{*}{ Model } & \multirow{2}{*}{ Process (explanatory) variables } & \multicolumn{3}{|c|}{ Intention Strength } & \multicolumn{3}{|c|}{$\begin{array}{c}\text { Direct Estimation of } \\
\text { Intention }\end{array}$} & \multicolumn{3}{|c|}{ Simulated Behavior $^{a}$} & \multicolumn{3}{|c|}{ Self-reported Behavior (12m) } \\
\hline & & $B$ & $\beta$ & $R_{a d j}^{2}$ & $B$ & $\beta$ & $R_{a d j}^{2}$ & $B$ & $\beta$ & $R_{a d j}^{2}$ & $B$ & $\beta$ & $R_{a d j}^{2}$ \\
\hline \multirow{3}{*}{ ТPB } & Attitude & $0.57 * *$ & 0.54 & \multirow{3}{*}{0.75} & $1.09 * *$ & 0.54 & \multirow{3}{*}{0.40} & -- & -- & -- & -- & -- & -- \\
\hline & Subjective Norm & $0.33 * *$ & 0.33 & & 0.15 & 0.08 & & -- & -- & -- & -- & -- & -- \\
\hline & PBC & $0.14 * *$ & 0.14 & & 0.14 & 0.07 & & -- & -- & -- & -- & -- & -- \\
\hline \multirow{2}{*}{ TPB } & PBC & -- & -- & -- & -- & -- & -- & 0.10 & 0.05 & \multirow{2}{*}{0.05} & 0.11 & 0.04 & \multirow{2}{*}{0.10} \\
\hline & Intention Strength & -- & -- & -- & -- & -- & -- & $0.42 * *$ & 0.20 & & $0.72 * *$ & 0.31 & \\
\hline \multirow{2}{*}{ ТPB } & $\mathrm{PBC}$ & -- & -- & -- & -- & -- & -- & 0.20 & 0.09 & \multirow{2}{*}{0.02} & 0.18 & 0.08 & \multirow{2}{*}{0.15} \\
\hline & Direct Estimation of Intention & -- & -- & -- & -- & -- & -- & 0.11 & 0.10 & & $0.44 * *$ & 0.37 & \\
\hline \multirow{3}{*}{$\mathrm{SCT}$} & Outcome Expectations & $0.85^{* *}$ & 0.79 & \multirow{3}{*}{0.73} & $1.13 * *$ & 0.55 & & 0.01 & 0.01 & \multirow{3}{*}{0.05} & 0.03 & 0.01 & \multirow{3}{*}{0.12} \\
\hline & Self-Efficacy & $0.14 * *$ & 0.15 & & $0.38 * *$ & 0.20 & 0.42 & 0.20 & 0.10 & & $0.35 * *$ & 0.16 & \\
\hline & Proximal Goals & -- & -- & & -- & -- & & 0.34 & 0.16 & & $0.57 *$ & 0.24 & \\
\hline \multirow{2}{*}{ LT v1 } & Anticipated Consequences & $0.19 * *$ & 0.20 & \multirow{2}{*}{0.69} & $0.48 * *$ & 0.28 & & 0.04 & 0.02 & \multirow{2}{*}{0.02} & 0.20 & 0.10 & \multirow{2}{*}{$0.0^{\top}$} \\
\hline & Evidence of Habit & $0.70 * *$ & 0.75 & & $0.78 * *$ & 0.43 & 0.33 & $0.26 *$ & 0.14 & & $0.51 *$ & 0.24 & \\
\hline \multirow{2}{*}{ LT v2 } & Anticipated Consequences & $0.47 * *$ & 0.27 & \multirow{2}{*}{0.32} & $0.47 * *$ & 0.27 & 032 & 0.02 & 0.01 & \multirow{2}{*}{0.02} & 0.16 & 0.08 & \multirow{2}{*}{0.14} \\
\hline & Self-reported Habit Index & $0.76^{* *}$ & 0.43 & & $0.76 * *$ & 0.43 & 0.32 & $0.29 * *$ & 0.16 & & $0.74 * *$ & 0.35 & \\
\hline $\mathrm{n} / \mathrm{a}$ & Self-reported Habit Index & $0.59 * *$ & 0.66 & 0.43 & $0.89 * *$ & 0.50 & 0.25 & $0.30 * *$ & 0.16 & 0.02 & $0.77 * *$ & 0.37 & 0.14 \\
\hline \multirow{2}{*}{ Planning } & Action Planning & -- & -- & -- & -- & -- & -- & 0.11 & 0.04 & \multirow{2}{*}{0.00} & $0.57 * *$ & 0.19 & \multirow{2}{*}{0.06} \\
\hline & Coping Planning & -- & -- & -- & -- & -- & -- & 0.12 & 0.07 & & 0.20 & 0.10 & \\
\hline
\end{tabular}

$* * \mathrm{p}<0.01 ; * \mathrm{p}<0.05 ; \mathrm{PBC}=$ perceived behavioral control

${ }^{a}$ only a subset $(\mathrm{N}=46)$ of nurses completed this portion of the behavior simulation and predictive constructs 
Supplemental Table 5.3

Predicting intention and reported foot examination

\begin{tabular}{|c|c|c|c|c|c|c|c|c|c|c|c|c|c|c|}
\hline \multirow{2}{*}{ Model } & \multirow{2}{*}{ Process (explanatory) variables } & \multicolumn{3}{|c|}{ Intention Strength } & & \multicolumn{3}{|c|}{$\begin{array}{l}\text { Direct Estimation of } \\
\text { Intention }\end{array}$} & \multicolumn{3}{|c|}{ Simulated Behavior ${ }^{a}$} & \multicolumn{3}{|c|}{$\begin{array}{c}\text { Self-reported Behavior } \\
(12 \mathrm{~m})\end{array}$} \\
\hline & & $B$ & $\beta$ & $R_{(a d j)}^{2}$ & & $B$ & $\beta$ & $R_{(a d j)}^{2}$ & $B$ & $\beta$ & $R_{(a d j)}^{2}$ & $B$ & $\beta$ & $R_{(a d j)}^{2}$ \\
\hline \multirow{3}{*}{ ТРB } & Attitude & $0.30 * *$ & 0.18 & \multirow{3}{*}{0.73} & & $0.43 *$ & 0.13 & \multirow{3}{*}{0.50} & -- & -- & -- & -- & -- & -- \\
\hline & Subjective Norm & $0.73 * *$ & 0.66 & & & $1.34 * *$ & 0.59 & & -- & -- & -- & -- & -- & -- \\
\hline & PBC & $0.18 * *$ & 0.12 & & & 0.18 & 0.06 & & -- & -- & -- & -- & -- & -- \\
\hline \multirow{2}{*}{ ТPB } & $\mathrm{PBC}$ & -- & -- & -- & & -- & -- & -- & 0.10 & 0.05 & \multirow{2}{*}{0.13} & 0.23 & 0.08 & \multirow{2}{*}{0.48} \\
\hline & Intention Strength & -- & -- & -- & & -- & -- & -- & $0.57 * *$ & 0.35 & & $1.54 * *$ & 0.65 & \\
\hline \multirow{2}{*}{ ТPB } & $\mathrm{PBC}$ & -- & -- & -- & & -- & -- & -- & 0.23 & 0.10 & \multirow{2}{*}{0.11} & $0.67 * *$ & 0.23 & \multirow{2}{*}{0.49} \\
\hline & Direct Estimation of Intention & -- & -- & -- & & -- & -- & -- & $0.23 * *$ & 0.30 & & $0.65 * *$ & 0.59 & \\
\hline \multirow{3}{*}{$\mathrm{SCT}$} & Outcome Expectations & $1.07 * *$ & 0.66 & \multirow{2}{*}{0.58} & & $1.70 * *$ & 0.52 & \multirow{2}{*}{0.37} & -0.15 & -0.06 & \multirow{3}{*}{0.15} & $-0.52 *$ & -0.15 & \multirow{3}{*}{0.50} \\
\hline & Self-Efficacy - circulation & $0.23 * *$ & 0.18 & & & $0.44 * *$ & 0.16 & & $0.37 * *$ & 0.18 & & $0.53 * *$ & 0.20 & \\
\hline & Proximal Goals & -- & -- & -- & & -- & -- & -- & $0.52 * *$ & 0.33 & & $1.60 * *$ & 0.68 & \\
\hline \multirow{3}{*}{$\mathrm{SCT}$} & Outcome Expectations & $1.06^{* *}$ & 0.65 & \multirow{2}{*}{0.58} & & $1.66 * *$ & 0.51 & \multirow{2}{*}{0.37} & -0.16 & -0.06 & \multirow{3}{*}{0.15} & $-0.50^{*}$ & -0.14 & \multirow{3}{*}{0.50} \\
\hline & Self-Efficacy - sensation & $0.24 * *$ & 0.19 & & & $0.48 * *$ & 0.19 & & $0.38 * *$ & 0.19 & & $0.53 * *$ & 0.21 & \\
\hline & Proximal Goals & -- & -- & -- & -- & -- & -- & -- & $0.52 * *$ & 0.32 & & $1.58 * *$ & 0.67 & \\
\hline \multirow{2}{*}{ LT v1 } & Anticipated Consequences & -0.01 & -0.01 & & & -0.08 & -0.02 & \multirow{2}{*}{0.62} & -0.15 & -0.05 & \multirow{2}{*}{0.14} & -0.07 & -0.02 & \multirow{2}{*}{0.43} \\
\hline & Evidence of Habit & $0.90 * *$ & 0.92 & 0.85 & & $1.59 * *$ & 0.80 & & $0.62 * *$ & 0.39 & & $1.48 * *$ & 0.67 & \\
\hline \multirow{2}{*}{ LT v2 } & Anticipated Consequences & 0.10 & & \multirow{2}{*}{0.66} & & 0.05 & 0.01 & 055 & -0.07 & -0.02 & 013 & 0.08 & 0.02 & 046 \\
\hline & Self-reported Habit Index & $0.86 * *$ & 0.81 & & & $1.60 * *$ & 0.74 & $0.3 J$ & $0.64 * *$ & 0.37 & & $1.48 * *$ & 0.68 & 0.40 \\
\hline $\mathrm{n} / \mathrm{a}$ & Self-reported Habit Index & $0.87 * *$ & 0.82 & 0.67 & & $1.61 * *$ & 0.74 & 0.55 & $0.61 * *$ & 0.36 & 0.13 & $1.49 * *$ & 0.68 & 0.46 \\
\hline Plannino & Action Planning & -- & -- & -- & & -- & -- & -- & 0.25 & 0.09 & 005 & $0.69 *$ & 0.18 & 032 \\
\hline & Coping Planning & -- & -- & -- & & -- & -- & -- & $0.31 *$ & 0.17 & 0.03 & $1.03 * *$ & 0.44 & 0.32 \\
\hline
\end{tabular}

$* * \mathrm{p}<0.01 ; * \mathrm{p}<0.05 ; \mathrm{PBC}=$ perceived behavioral control

a only a subset $(\mathrm{N}=165)$ of GPs completed this portion of the behavior simulation and predictive constructs

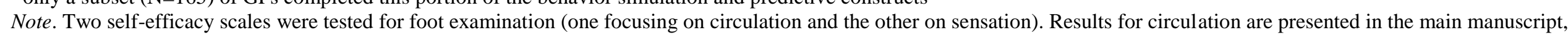
and are consistent with results for sensation. 
Supplemental Table 5.4

Predicting intention and reported provision of self-management advice

\begin{tabular}{|c|c|c|c|c|c|c|c|c|c|c|c|c|c|}
\hline \multirow{2}{*}{ Model } & \multirow{2}{*}{$\begin{array}{c}\text { Process (explanatory) } \\
\text { variables }\end{array}$} & \multicolumn{3}{|c|}{ Intention Strength } & \multicolumn{3}{|c|}{$\begin{array}{l}\text { Direct Estimation of } \\
\text { Intention }\end{array}$} & \multicolumn{3}{|c|}{ Simulated Behavior } & \multicolumn{3}{|c|}{$\begin{array}{c}\text { Self-reported Behavior } \\
(12 \mathrm{~m})\end{array}$} \\
\hline & & $B$ & $\beta$ & $R_{(a d j)}^{2}$ & $B$ & $\beta$ & $R_{(a d j)}^{2}$ & $B$ & $\beta$ & $R_{(a d j)}^{2}$ & $B$ & $\beta$ & $R_{(a d j)}^{2}$ \\
\hline \multirow{3}{*}{ ТPB } & Attitude & $0.38 * *$ & 0.26 & \multirow{3}{*}{0.72} & $0.56 * *$ & 0.19 & \multirow{3}{*}{0.37} & -- & -- & -- & -- & -- & -- \\
\hline & Subjective Norm & $0.42 * *$ & 0.38 & & $0.50 * *$ & 0.28 & & -- & -- & -- & -- & -- & -- \\
\hline & $\mathrm{PBC}$ & $0.37 * *$ & 0.36 & & $0.62 * *$ & 0.30 & & -- & -- & -- & -- & -- & -- \\
\hline \multirow{2}{*}{ ТPB } & $\mathrm{PBC}$ & -- & -- & -- & -- & -- & -- & 0.17 & 0.08 & \multirow{2}{*}{0.06} & 0.25 & 0.12 & \multirow{2}{*}{0.17} \\
\hline & Intention Strength & -- & -- & -- & -- & -- & -- & $0.42 * *$ & 0.19 & & $0.67 * *$ & 0.33 & \\
\hline \multirow[b]{2}{*}{ ТРВ } & PBC & -- & -- & -- & -- & -- & -- & 0.18 & 0.09 & \multirow[b]{2}{*}{0.09} & $0.34 * *$ & 0.17 & \multirow[b]{2}{*}{0.19} \\
\hline & $\begin{array}{l}\text { Direct Estimation of } \\
\text { Intention }\end{array}$ & & & -- & -- & -- & -- & $0.29 * *$ & 0.25 & & $0.36 * *$ & 0.34 & \\
\hline \multirow{3}{*}{ SCT } & Outcome Expectations & $0.82 * *$ & 0.57 & \multirow{2}{*}{0.62} & $0.90 * *$ & 0.31 & \multirow{3}{*}{0.34} & -0.22 & -0.07 & \multirow{3}{*}{0.07} & -0.09 & -0.03 & \multirow{3}{*}{0.18} \\
\hline & Self-Efficacy & $0.36 * *$ & 0.32 & & $0.79 * *$ & 0.36 & & $0.42 * *$ & 0.18 & & $0.40 * *$ & 0.18 & \\
\hline & Proximal Goals & -- & -- & -- & -- & -- & & $0.42 *$ & 0.19 & & $0.66^{* *}$ & 0.32 & \\
\hline \multirow[t]{2}{*}{ LT v1 } & $\begin{array}{l}\text { Anticipated } \\
\text { Consequences }\end{array}$ & 0.03 & 0.03 & \multirow[t]{2}{*}{0.85} & -.01 & $<-.01$ & \multirow[t]{2}{*}{0.44} & -.01 & $<-.01$ & \multirow[t]{2}{*}{0.04} & $0.24 *$ & 0.11 & \multirow[t]{2}{*}{0.19} \\
\hline & Evidence of Habit & $0.88 * *$ & 0.91 & & $1.27 * *$ & 0.67 & & $0.47 * *$ & 0.22 & & $0.80 * *$ & 0.41 & \\
\hline \multirow{2}{*}{ LT v2 } & $\begin{array}{l}\text { Anticipated } \\
\text { Consequences }\end{array}$ & $0.13 * *$ & 0.11 & \multirow{2}{*}{0.58} & 0.09 & 0.04 & \multirow{2}{*}{0.39} & 0.03 & 0.01 & \multirow{2}{*}{0.05} & $0.32 *$ & 0.14 & \multirow{2}{*}{0.19} \\
\hline & $\begin{array}{l}\text { Self-reported Habit } \\
\text { Index }\end{array}$ & $0.64 * *$ & 0.74 & & $1.09 * *$ & 0.62 & & $0.42 * *$ & 0.22 & & $0.69 * *$ & 0.39 & \\
\hline $\mathrm{n} / \mathrm{a}$ & $\begin{array}{l}\text { Self-reported Habit } \\
\text { Index }\end{array}$ & $0.66^{* *}$ & 0.76 & 0.57 & $1.10 * *$ & 0.63 & 0.39 & $0.42 * *$ & 0.22 & 0.05 & $0.74 * *$ & 0.41 & 0.17 \\
\hline \multirow{2}{*}{ Planning } & Action Planning & -- & -- & -- & -- & -- & -- & 0.24 & 0.11 & \multirow{2}{*}{0.03} & 0.21 & 0.11 & \multirow{2}{*}{0.14} \\
\hline & Coping Planning & -- & -- & -- & -- & -- & -- & 0.21 & 0.11 & & $0.51 * *$ & 0.30 & \\
\hline
\end{tabular}

$* * \mathrm{p}<0.01 ; * \mathrm{p}<0.05 ; \mathrm{PBC}=$ perceived behavioral control 
Supplemental Table 5.5

Predicting intention and reported prescription of additional therapy for management of glycemic control

\begin{tabular}{|c|c|c|c|c|c|c|c|c|c|c|c|c|c|}
\hline \multirow{2}{*}{ Model } & \multirow{2}{*}{$\begin{array}{c}\text { Process (explanatory) } \\
\text { variables }\end{array}$} & \multicolumn{3}{|c|}{ Intention Strength } & \multicolumn{3}{|c|}{$\begin{array}{c}\text { Direct Estimation of } \\
\text { Intention }\end{array}$} & \multicolumn{3}{|c|}{ Simulated Behavior $^{a}$} & \multicolumn{3}{|c|}{$\begin{array}{c}\text { Self-reported Behavior } \\
(12 \mathrm{~m})\end{array}$} \\
\hline & & $B$ & $\beta$ & $R_{a d j}^{2}$ & $B$ & $\beta$ & $R_{a d j}^{2}$ & $B$ & $\beta$ & $R_{a d j}^{2}$ & $B$ & $\beta$ & $R_{a d j}^{2}$ \\
\hline \multirow{3}{*}{ ТPB } & Attitude & $0.48 * *$ & 0.4 & \multirow{3}{*}{0.65} & $0.76^{* *}$ & 0.3 & \multirow{3}{*}{0.24} & -- & -- & -- & -- & -- & -- \\
\hline & Subjective Norm & $0.38 * *$ & 0.4 & & $0.34^{*}$ & 0.2 & & -- & -- & -- & -- & -- & -- \\
\hline & $\mathrm{PBC}$ & $0.15^{* *}$ & 0.2 & & $0.23 *$ & 0.1 & & -- & -- & -- & -- & -- & -- \\
\hline \multirow{2}{*}{ ТPB } & $\mathrm{PBC}$ & -- & -- & -- & -- & -- & -- & -0.05 & -0.04 & \multirow{2}{*}{0.01} & 0.25 & 0.11 & \multirow{2}{*}{0.09} \\
\hline & Intention Strength & -- & -- & -- & -- & -- & -- & 0.16 & 0.12 & & $0.60 * *$ & 0.24 & \\
\hline \multirow[b]{2}{*}{ ТPB } & PBC & -- & -- & -- & -- & -- & -- & -0.01 & -0.01 & \multirow[b]{2}{*}{-0.01} & 0.22 & 0.09 & \multirow[b]{2}{*}{0.19} \\
\hline & $\begin{array}{l}\text { Direct Estimation of } \\
\text { Intention }\end{array}$ & -- & -- & -- & -- & -- & -- & 0.02 & 0.03 & & $0.51 * *$ & 0.40 & \\
\hline \multirow{3}{*}{$\mathrm{SCT}$} & Outcome Expectations & $0.87 * *$ & 0.72 & \multirow{2}{*}{0.60} & $0.92 * *$ & 0.37 & \multirow{2}{*}{0.25} & 0.08 & 0.05 & \multirow{3}{*}{0.00} & -0.06 & -0.02 & \multirow{3}{*}{0.10} \\
\hline & Self-Efficacy & $0.10^{* *}$ & 0.12 & & $0.40 * *$ & 0.23 & & -0.02 & -0.02 & & $0.38 * *$ & 0.17 & \\
\hline & Proximal Goals & -- & -- & -- & -- & -- & -- & 0.09 & 0.07 & & $0.58 *$ & 0.23 & \\
\hline \multirow{2}{*}{ LT v1 } & $\begin{array}{l}\text { Anticipated } \\
\text { Consequences }\end{array}$ & 0.03 & 0 & \multirow{2}{*}{0.71} & 0.07 & 0 & \multirow{2}{*}{0.23} & -0.09 & -0.07 & \multirow{2}{*}{0.00} & 0.18 & 0.08 & \multirow{2}{*}{0.11} \\
\hline & Evidence of Habit & $0.78 * *$ & 0.8 & & $0.91 * *$ & 0.5 & & 0.11 & 0.09 & & $0.74 * *$ & 0.31 & \\
\hline \multirow[b]{2}{*}{ LT v2 } & $\begin{array}{l}\text { Anticipated } \\
\text { Consequences }\end{array}$ & $0.11 *$ & 0.1 & \multirow[b]{2}{*}{0.32} & 0.09 & 0.1 & \multirow[b]{2}{*}{0.19} & -0.06 & -0.05 & \multirow[b]{2}{*}{0.00} & 0.20 & 0.09 & \multirow[b]{2}{*}{0.12} \\
\hline & $\begin{array}{l}\text { Self-reported Habit } \\
\text { Index }\end{array}$ & $0.40 * *$ & 0.53 & & $0.66^{* *}$ & 0.43 & & 0.03 & 0.03 & & $0.61 * *$ & 0.32 & \\
\hline $\mathrm{n} / \mathrm{a}$ & $\begin{array}{l}\text { Self-reported Habit } \\
\text { Index }\end{array}$ & $0.42 * *$ & 0.6 & 0.30 & $0.68 * *$ & 0.4 & 0.19 & 0.02 & 0.02 & 0.00 & $0.65 * *$ & 0.34 & 0.11 \\
\hline \multirow{2}{*}{ Planning } & Action Planning & -- & -- & -- & -- & -- & -- & -0.15 & -0.13 & \multirow{2}{*}{0.00} & $0.38 *$ & 0.16 & \multirow{2}{*}{0.08} \\
\hline & Coping Planning & -- & -- & -- & -- & -- & -- & 0.08 & 0.08 & & $0.29 *$ & 0.16 & \\
\hline
\end{tabular}

$* * \mathrm{p}<0.01 ; * \mathrm{p}<0.05 ; \mathrm{PBC}=$ perceived behavioral control

${ }^{a}$ only a subset $(\mathrm{N}=52)$ of nurses completed this portion of the simulated behavior and predictive constructs 
Supplemental Table 5.6

Predicting intention and reported provision of general education

\begin{tabular}{|c|c|c|c|c|c|c|c|c|c|c|c|c|c|}
\hline \multirow{2}{*}{ Model } & \multirow{2}{*}{$\begin{array}{c}\text { Process (explanatory) } \\
\text { variables }\end{array}$} & \multicolumn{3}{|c|}{ Intention Strength } & \multicolumn{3}{|c|}{$\begin{array}{l}\text { Direct Estimation of } \\
\text { Intention }\end{array}$} & \multicolumn{3}{|c|}{ Simulated Behavior } & \multicolumn{3}{|c|}{$\begin{array}{c}\text { Self-reported Behavior } \\
(12 \mathrm{~m})\end{array}$} \\
\hline & & $B$ & $\beta$ & $R_{(a d j)}^{2}$ & $B$ & $\beta$ & $R_{(a d j)}^{2}$ & $B$ & $\beta$ & $R_{(a d j)}^{2}$ & $B$ & $\beta$ & $R_{(a d j)}^{2}$ \\
\hline \multirow{3}{*}{ TPB } & Attitude & $0.36 * *$ & 0.26 & \multirow{3}{*}{0.70} & $0.88 * *$ & 0.31 & \multirow{3}{*}{0.33} & -- & -- & -- & -- & -- & -- \\
\hline & Subjective Norm & $0.35 * *$ & 0.37 & & $0.31 * *$ & 0.17 & & -- & -- & -- & -- & -- & -- \\
\hline & PBC & $0.37 * *$ & 0.40 & & $0.42 * *$ & 0.23 & & -- & -- & -- & -- & -- & -- \\
\hline \multirow{2}{*}{ ТРB } & $\mathrm{PBC}$ & -- & -- & -- & -- & -- & -- & $0.18 * *$ & 0.08 & \multirow{2}{*}{0.06} & $0.35^{* *}$ & 0.17 & \multirow{2}{*}{0.19} \\
\hline & Intention Strength & -- & -- & -- & -- & -- & -- & 0.45 & 0.18 & & $0.76^{* *}$ & 0.32 & \\
\hline \multirow[b]{2}{*}{ TPB } & $\mathrm{PBC}$ & -- & -- & -- & -- & -- & -- & 0.26 & 0.12 & \multirow[b]{2}{*}{0.07} & $0.41 * *$ & 0.20 & \multirow[b]{2}{*}{0.32} \\
\hline & $\begin{array}{l}\text { Direct Estimation of } \\
\text { Intention }\end{array}$ & -- & -- & -- & -- & -- & -- & 0.24 & 0.20 & & $0.52 * *$ & 0.46 & \\
\hline \multirow{3}{*}{ SCT } & Outcome Expectations & $0.80 * *$ & 0.59 & \multirow{2}{*}{0.59} & $1.26 * *$ & 0.46 & \multirow{2}{*}{0.30} & -0.07 & -0.02 & \multirow{3}{*}{0.06} & -0.05 & -0.02 & \multirow{3}{*}{0.19} \\
\hline & Self-Efficacy & $0.28 * *$ & 0.30 & & $0.32 * *$ & 0.17 & & 0.26 & 0.11 & & $0.26^{*}$ & 0.13 & \\
\hline & Proximal Goals & -- & -- & -- & -- & -- & -- & $0.46^{*}$ & 0.19 & & $0.89 * *$ & 0.38 & \\
\hline \multirow[t]{2}{*}{ LT v1 } & $\begin{array}{l}\text { Anticipated } \\
\text { Consequences }\end{array}$ & 0.02 & 0.02 & \multirow[t]{2}{*}{0.81} & 0.08 & 0.04 & \multirow[t]{2}{*}{0.37} & 0.08 & 0.04 & \multirow[t]{2}{*}{0.05} & 0.05 & 0.03 & \multirow[t]{2}{*}{0.22} \\
\hline & Evidence of Habit & $0.81 * *$ & 0.90 & & $1.07 * *$ & 0.60 & & $0.50 * *$ & 0.22 & & $0.98 * *$ & 0.47 & \\
\hline \multirow[t]{2}{*}{ LT v2 } & $\begin{array}{l}\text { Anticipated } \\
\text { Consequences }\end{array}$ & $0.10 * *$ & 0.11 & \multirow[t]{2}{*}{0.54} & $0.19 *$ & 0.10 & \multirow[t]{2}{*}{0.29} & 0.13 & 0.06 & \multirow[t]{2}{*}{0.04} & 0.16 & 0.08 & \multirow[t]{2}{*}{0.14} \\
\hline & Self-reported Habit Index & $0.56^{* *}$ & 0.71 & & $0.82 * *$ & 0.52 & & $0.36 * *$ & 0.19 & & $0.64 * *$ & 0.36 & \\
\hline $\mathrm{n} / \mathrm{a}$ & Self-reported Habit Index & $0.57 * *$ & 0.73 & 0.52 & $0.84 * *$ & 0.53 & 0.28 & $0.37 * *$ & 0.19 & 0.04 & $0.65^{* *}$ & 0.37 & 0.13 \\
\hline \multirow{2}{*}{ Planning } & Action Planning & -- & -- & -- & -- & -- & -- & 0.25 & 0.12 & \multirow{2}{*}{0.04} & $0.71 * *$ & 0.36 & \multirow{2}{*}{0.19} \\
\hline & Coping Planning & -- & -- & -- & -- & -- & -- & $0.26^{*}$ & 0.13 & & $0.21 *$ & 0.12 & \\
\hline
\end{tabular}

$* * \mathrm{p}<0.01 ; * \mathrm{p}<0.05 ; \mathrm{PBC}=$ perceived behavioral control 